\title{
Iodine-125 seed radiation induces ROS-mediated apoptosis, autophagy and paraptosis in human esophageal squamous cell carcinoma cells
}

\author{
CHAO WANG ${ }^{1}$, TIAN-KUAN LI ${ }^{1}$, CHU-HUI ZENG ${ }^{1}$, RUI FAN ${ }^{1}$, \\ YONG WANG $^{2}$, GUANG-YU ZHU ${ }^{2}$ and JIN-HE GUO ${ }^{1,2}$ \\ ${ }^{1}$ Jiangsu Key Laboratory of Molecular and Functional Imaging, Medical School; \\ ${ }^{2}$ Center of Interventional Radiology and Vascular Surgery, Department of Radiology, Zhongda Hospital, \\ Southeast University, Nanjing, Jiangsu 210009, P.R. China
}

Received September 10, 2019; Accepted March 12, 2020

DOI: $10.3892 /$ or.2020.7576

\begin{abstract}
Iodine-125 ( $\left.{ }^{125} \mathrm{I}\right)$ seed brachytherapy has been proven to be a safe and effective treatment for advanced esophageal cancer; however, the mechanisms underlying its actions are not completely understood. In the present study, the anti-cancer mechanisms of ${ }^{125} \mathrm{I}$ seed radiation in human esophageal squamous cell carcinoma (ESCC) cells (Eca-109 and KYSE-150) were determined, with a particular focus on the mode of cell death. The results showed that ${ }^{125}$ I seed radiation significantly inhibited cell proliferation, and induced DNA damage and G2/M cell cycle arrest in both ESCC cell lines. ${ }^{125}$ I seed radiation induced cell death through both apoptosis and paraptosis. Eca-109 cells were primarily killed by inducing caspase-dependent apoptosis, with 6 Gy radiation resulting in the largest response. KYSE-150 cells were primarily killed by inducing paraptosis, which is characterized by extensive cytoplasmic vacuolation. ${ }^{125} \mathrm{I}$ seed radiation induced autophagic flux in both ESCC cell lines, and autophagy inhibition by 3-methyladenine enhanced radiosensitivity. Furthermore ${ }^{125}$ I seed radiation induced increased production of reactive oxygen species (ROS) in both ESCC cell lines. Treatment with an ROS scavenger significantly attenuated the effects of ${ }^{125} \mathrm{I}$ seed radiation on endoplasmic reticulum stress, autophagy, apoptosis, paraptotic vacuoles and reduced cell viability. In vivo experiments showed that ${ }^{125} \mathrm{I}$ seed brachytherapy induced ROS generation, initiated cell apoptosis and potential paraptosis, and inhibited cell proliferation and tumor growth. In summary, the results demonstrate that in ESCC cells, ${ }^{125} \mathrm{I}$
\end{abstract}

Correspondence to: Dr Jin-He Guo, Center of Interventional Radiology and Vascular Surgery, Department of Radiology, Zhongda Hospital, Southeast University, 87 Dingjiaqiao Road, Nanjing, Jiangsu 210009, P.R. China

E-mail: jinheguo@sina.com

Key words: ${ }^{125}$ I seed radiation, apoptosis, autophagy, paraptosis, esophageal cancer seed radiation induces cell death through both apoptosis and paraptosis; and at the same time initiates protective autophagy. Additionally, ${ }^{125}$ I seed radiation-induced apoptosis, paraptosis and autophagy was considerably mediated by ROS.

\section{Introduction}

Esophageal cancer is the seventh most common type of cancer and the sixth leading cause of cancer-associated death worldwide (1). In Asia, 90\% of patients with esophageal cancer have esophageal squamous cell carcinoma (ESCC) (2). The majority of patients with ESCC are diagnosed with an advanced stage cancer in the first instance, and therefore not eligible for surgery (2). Chemotherapy and radiotherapy are well-established treatments for patients with locally advanced esophageal cancer. However, severe adverse events and complications caused by chemotherapy and radiotherapy pose additional clinical challenges $(3,4)$. Brachytherapy via radioactive iodine-125 ( $\left.{ }^{125} \mathrm{I}\right)$ seeds, a method of continuous low-dose-rate irradiation, has been used to treat various types of unresectable or locally recurrent cancer (5-7). Compared with external beam radiotherapy (EBRT) using single/fractionated high-dose-rate irradiation, ${ }^{125} \mathrm{I}$ seed brachytherapy has the advantages of easy preparation, direct contact with tumor tissue, less radiation to adjacent normal tissues and a higher relative biological effect (RBE) on tumor cells $(8,9)$. A series of studies have reported that combination therapy of ${ }^{125}$ I seed brachytherapy and stent placement shows good tumor control and survival benefits in patients with advanced esophageal cancer (10-12). However, to the best of our knowledge, there are no studies examining the mechanisms underlying the anti-cancer effects of ${ }^{125} \mathrm{I}$ seed radiation in ESCC.

Apoptosis is the classic type of programmed cell death (PCD) and operates in a caspase-dependent manner. Following DNA damage and G2/M cell cycle arrest, apoptosis is considered the major mode of cell death induced by ${ }^{125}$ I seed radiation as reported in studies on various types of cancer, such as colorectal cancer (8), lung cancer (13) and pancreatic cancer (14). However, cancer cells inherently have several anti-apoptotic mechanisms, resulting in resistance 
to radiotherapy, and thus, cell survival (15). Other types of caspase-independent PCD include autophagy and paraptosis, and these may also participate in the anti-cancer mechanisms of ${ }^{125} \mathrm{I}$ seed radiation, but relevant studies are rare (16). Autophagy is an evolutionarily conserved process, in which cells degrade damaged cytoplasmic materials to facilitate survival, but excessive autophagy may also lead to autophagic cell death (ACD) $(17,18)$. Previous studies have suggested that EBRT-induced autophagy serves a protective role in ESCC (19,20); however, the association between autophagy and ${ }^{125}$ I seed radiation in ESCC has not yet been studied, to the best of our knowledge. Paraptosis, or paraptosis-like cell death, is characterized by cytoplasmic vacuolation resulting from mitochondria and/or endoplasmic reticulum (ER) swelling, and it lacks typical apoptotic morphological characteristics, including chromatin condensation, nuclear fragmentation and apoptotic body formation (21). Paraptosis differs from necrosis in that, paraptosis does not result in early plasma membrane rupture and the release of cellular contents $(21,22)$. Recent studies have shown that paraptosis-associated cell death is an important anti-cancer mechanism of various natural products, and is a novel area of interest in cancer research (23-26). It has been reported that photodynamic therapy may also induce paraptosis (27); however, aside from one report on colorectal cancer (16), radiation has not hitherto been associated with paraptosis.

In the present study, the modes and mechanisms of cell death induced by ${ }^{125} \mathrm{I}$ seed radiation in two human ESCC cell lines, Eca-109 and KYSE-150, were systematically investigated. ${ }^{125}$ I seed radiation kills KYSE-150 cells primarily by inducing paraptosis, rather than apoptosis. Oxidative stress, caused by an imbalance between the generation of reactive oxygen species (ROS) and the ability of the cell to clear oxidants, is critical for cellular proliferation and death (28). Herein, the roles of ROS in apoptosis, autophagy and paraptosis induced by ${ }^{125}$ I seed radiation in Eca-109 and KYSE-150 cells were further investigated.

\section{Materials and methods}

Reagents and antibodies. Annexin V-enhanced green fluorescent protein (EGFP)/propidium iodide (PI) apoptosis detection kit, cell cycle detection kit, DAPI, bicinchoninic acid assay kit, and cell lysis assay kit containing protease and phosphatase inhibitors were purchased from Nanjing Keygen Biotech, Co., Ltd. 2',7'-dichlorodihydrofluorescein diacetate (DCFH-DA) and trypan blue dye were purchased from Beyotime Institute of Biotechnology. In situ cell death detection TUNEL kit was purchased from Roche Diagnostics GmbH. 3-Methyladenine (3-MA) and rapamycin were purchased from Selleck Chemicals. N-Acetyl-L-cysteine (NAC) was purchased from Sigma-Aldrich (Merck $\mathrm{KGaA}$ ). Cycloheximide (CHX) was purchased from MedChem Express. Rabbit monoclonal antibodies against $\beta$-actin (cat. no. 4970), $\gamma$-H2AX (cat. no. 9718), caspase-3 (cat. no. 9662), cleaved caspase-3 (cat. no. 9664), LC3 (cat. no. 3868), CHOP (cat. no. 5554) and Ki-67 (cat. no. 9027) were obtained from Cell Signaling Technology, Inc. Rabbit polyclonal antibodies against p62 (cat. no. 18420) and Grp78/Bip (cat. no. 11587) were obtained from ProteinTech
Group, Inc. Horseradish peroxidase (HRP)-conjugated goat anti-rabbit secondary antibody (cat. no. G-21234) and Alexa Fluor 488-conjugated goat anti-rabbit secondary antibody (cat. no. A-11008) were obtained from Invitrogen (Thermo Fisher Scientific, Inc.).

${ }^{125}$ I seed irradiation.${ }^{125}$ Iradioactive seeds $(0.8 \mathrm{mCi}$, model 6711$)$ were kindly provided by Shanghai Xinke Pharmaceutical, Co., Ltd. The ${ }^{125}$ I seed irradiation model used in the present study was designed according to previous studies $(29,30)$, and was designed to provide a relatively homogeneous dose distribution in vitro. This model consisted of a lower irradiation plane and an upper treatment plane (the bottom of a $35-\mathrm{mm}$ polystyrene dish). The height between the irradiation plane and treatment plane was $6 \mathrm{~mm}$. In the irradiation plane, 8 seeds with the same activity were equidistantly spaced around a $35-\mathrm{mm}$ diameter circumference, and a ninth seed was confined to the center. The initial dose rate in the treatment plane was $2.7 \mathrm{cGy} / \mathrm{h}$, and the exposure time for delivering cumulative radiation doses of 2, 4, 6 or 8 Gy were 74, 151, 230 and 312 h, respectively. For the cells in the control group, sham seeds (without radioactivity) were used.

Cell lines and culture. The human ESCC cell lines Eca-109 and KYSE-150 were obtained from The Cell Bank of Type Culture Collection of the Chinese Academy of Sciences. The cells were maintained in RPMI 1640 medium (Hyclone; GE Healthcare), containing 10\% FBS (Gibco; Thermo Fisher Scientific, Inc.) and $1 \%$ penicillin/streptomycin (Hyclone; GE Healthcare), in a $5 \% \mathrm{CO}_{2}$ atmosphere at $37^{\circ} \mathrm{C}$. In certain experiments, the cells were incubated with $0.5 \mathrm{mM} 3-\mathrm{MA}$, $2 \mu \mathrm{M}$ CHX or $5 \mathrm{mM}$ NAC.

Colony formation assay. After 2, 4, 6 or 8 Gy irradiation, cells were cultured without radiation for 8-10 days to form colonies. Subsequently, cells were fixed with $4 \%$ paraformaldehyde for $10 \mathrm{~min}$ at room temperature and then stained with $0.1 \%$ crystal violet solution for $20 \mathrm{~min}$ at room temperature. The planting efficiency (PE) was defined as the ratio of colony number to inoculating cell number, and the survival fraction (SF) was calculated as follows: $\mathrm{SF}=\mathrm{PE}$ (irradiated group)/PE (control group) $\times 100 \%$. Cell survival curves were fitted using a multi-target single-hit model: $\mathrm{SF}=1-\left(1-\mathrm{e}^{\mathrm{D} / \mathrm{D} 0}\right)^{\mathrm{N}}$.

Cell viability assay. After $48 \mathrm{~h}$ of the indicated treatments, the cells were suspended and stained with trypan blue dye for $3 \mathrm{~min}$ at room temperature. Cell viability was determined using a trypan blue exclusion assay and observed under a light microscope (magnification, x100; Eclipse TS100; Nikon Corporation).

Cell cycle and apoptosis assay. Cells were collected $48 \mathrm{~h}$ after irradiation. For cell cycle analysis, cells were fixed with $70 \%$ ethanol overnight at $4^{\circ} \mathrm{C}$ and then stained with $\mathrm{PI} /$ ribonuclease A for $30 \mathrm{~min}$ at room temperature in the dark. For apoptosis analysis, the cells were stained with Annexin V-EGFP and PI for $20 \mathrm{~min}$ at room temperature in the dark. Samples were analyzed by flow cytometry (NovoCyte 2060R, ACEA Biosciences, Inc.) using NovoExpress software version 1.3.0 (ACEA Biosciences, Inc.). 
Intracellular ROS generation levels. After $48 \mathrm{~h}$ of the indicated treatments, the cells were incubated with $10 \mu \mathrm{M}$ DCFH-DA for $30 \mathrm{~min}$ at $37^{\circ} \mathrm{C}$ in the dark. Subsequently, the cells were washed with PBS, and then collected for flow cytometry analysis.

Transmission electron microscopy (TEM). A total of $48 \mathrm{~h}$ after irradiation, the cells were collected and fixed in $2.5 \%$ glutaraldehyde phosphate buffer overnight at $4^{\circ} \mathrm{C}$, washed with PBS, and then fixed in $1 \%$ osmium tetroxide for $2 \mathrm{~h}$ at $4^{\circ} \mathrm{C}$. Subsequently, the fixed cells were washed with PBS, dehydrated in 50-100\% ethanol, and then embedded in epoxy resin. After polymerization for $48 \mathrm{~h}$ at $60^{\circ} \mathrm{C}$, the ultrathin sections were stained with uranyl for $15 \mathrm{~min}$ and lead acetate for $10 \mathrm{~min}$ both at room temperature, and examined under a transmission electron microscope (H-7650; Hitachi, Ltd.).

Immunofluorescence microscopy. Cells were cultured on coverslips in 35-mm dishes. Following irradiation and culturing for $48 \mathrm{~h}$, cells were fixed with ice-cold methanol for $5 \mathrm{~min}$ at $-20^{\circ} \mathrm{C}$ and subsequently blocked in $5 \%$ BSA for $1 \mathrm{~h}$ at room temperature. Fixed cells were incubated with primary antibodies (LC3, 1:200; $\gamma$-H2AX, 1:200) overnight at $4{ }^{\circ} \mathrm{C}$, washed with PBS, and then incubated with Alexa Fluor 488-conjugated secondary antibodies (1:500) for $1 \mathrm{~h}$ at room temperature. Nuclei were stained with DAPI for $10 \mathrm{~min}$ at room temperature and the cells were examined under a fluorescence microscope (magnification, x200; BX53, Olympus Corporation).

Western blot analysis. Cells were lysed in the ice-cold lysis buffer, containing freshly added protease and phosphatase inhibitors. Cell lysates were centrifuged for $15 \mathrm{~min}$ at $16,000 \mathrm{xg}$ at $4^{\circ} \mathrm{C}$, and the concentration of protein supernatants was determined using a bicinchoninic acid assay. The protein supernatants were boiled in loading buffer for $5 \mathrm{~min}$, loaded on an SDS-gel. resolved by SDS-PAGE, and transferred to PVDF membranes. The membranes were blocked in 5\% BSA in Tris-buffered saline solution containing $0.05 \%$ Tween-20 (TBST) for $1 \mathrm{~h}$ at room temperature, incubated with the indicated primary antibodies ( $\beta$-actin, 1:1,000; $\gamma$-H2AX, 1:1,000; caspase-3, 1:1,000; cleaved caspase-3, 1:1,000; LC3, 11,:000; p62, 1:2,000; Grp78/Bip, 1:4,000; CHOP, 1:1,000) overnight at $4^{\circ} \mathrm{C}$, washed with TBST, and then incubated with the HRP-conjugated secondary antibody $(1: 3,000)$ for $1 \mathrm{~h}$ at room temperature. Antibody-antigen complexes were detected using an enhanced chemiluminescence kit (Tiangen Biotech, Co., Ltd.) and a light capture system (Clinx Science Instruments, Co., Ltd.). Densitometry analysis was performed using ImageJ version 1.51 (National Institutes of Health). $\beta$-actin was used as a loading control.

Animal xenograft analysis. Eca-109 or KYSE-150 cells $\left(5 \times 10^{6}\right.$ in $\left.0.1 \mathrm{ml} \mathrm{PBS}\right)$ were injected subcutaneously into the left axilla of female BALB/c nude mice. Tumor volumes were measured every three days using the following formula: Volume $=$ length $\mathrm{x}$ width $^{2} \mathrm{x} 0.5$. When the average tumor volume reached $300 \mathrm{~mm}^{3}$ (after $\sim 12$ days for Eca-109 cells or 18 days for KYSE-150 cells), the mice were randomized into two groups ( $\mathrm{n}=6$ per group): Control group and the ${ }^{125}$ I seed group. For mice in the ${ }^{125}$ I seed group, an 18-gauge needle was punctured into the center of the tumor mass, and then the ${ }^{125} \mathrm{I}$ seed $(0.8 \mathrm{mCi})$ was implanted using a Mick applicator. For the control group, only tumor puncture was performed. All mice were euthanized 15 days after treatment, and the cumulative dose in the ${ }^{125}$ I seed group was $\sim 20 \mathrm{~Gy}$. Tumor specimens were harvested and weighed, and then processed for histological analysis.

Tumor specimens were fixed in $4 \%$ paraformaldehyde for $48 \mathrm{~h}$ at room temperature and embedded in paraffin. Tumor sections (4 $\mu \mathrm{m}$ thickness) were subsequently used for hematoxylin and eosin (H\&E) staining, TUNEL assay, and immunohistochemistry staining. TUNEL assay was performed according to the manufacturer's protocol. Immunohistochemistry was performed as described previously (23) using primary antibodies against Ki-67 (1:400; overnight at $\left.4^{\circ} \mathrm{C}\right)$. HRP-conjugated secondary antibody $(1: 1,000 ; 30 \mathrm{~min}$ at room temperature) and diaminobenzidine were used for detection. Frozen tumor sections were used for detection of ROS using DCFH-DA staining, as described above. After incubation with DCFH-DA, tumor sections were counter stained with DAPI for $10 \mathrm{~min}$ at room temperature.

All experiments involving mice were performed in accordance with the guidelines on animal care and experiments on laboratory animals of the Center of Experimental Animals, Southeast University (Nanjing, China), and were approved by the Animal Experimental Ethics Committee of Southeast University (approval no. 20190225004). Humane endpoints included mice exhibiting poor physical conditions, confined activities affected by the tumor, tumor sizes $>2.0 \mathrm{~cm}$ in diameter $\left(4.0 \mathrm{~cm}^{3}\right)$, and severe tumor ulceration, necrosis or infection.

Statistical analysis. All experiments were performed in triplicate. Data are expressed as the mean \pm standard deviation. A Student's t-test or one-way ANOVA followed by a post-hoc Tukey's test was used to detect differences. $\mathrm{P}<0.05$ was considered to indicate a statistically significant difference. All analyses were performed using SPSS version 23.0 (IBM, Corp.).

\section{Results}

${ }^{125}$ I seed radiation reduces proliferation and induces cytoplasmic vacuolation. To investigate the anti-cancer effects of ${ }^{125}$ I seed radiation, Eca-109 and KYSE-150 cells were irradiated at different radiation doses (up to $8 \mathrm{~Gy}$ ). As shown in Fig. 1A, the effects on cell proliferation were increased as the cumulative dose administered was increased. The SF values of $8 \mathrm{~Gy}$ were $0.04 \pm 0.01$ for Eca- 109 cells and $0.02 \pm 0.01$ for KYSE-150 cells ( $\mathrm{P}=0.099)$. In Eca-109 cells, the number of multinucleated giant cells (MNGCs) increased following irradiation, and cytoplasmic vacuolation was observed. The cytoplasmic vacuoles were primarily observed in MNGCs, and the number as well as the size of the vacuoles increased over time (Fig. 1B). In KYSE-150 cells, extensive cytoplasmic vacuolation was observed following irradiation, and the number of vacuolated cells increased in a dose-dependent manner (Fig. 1C). 
A
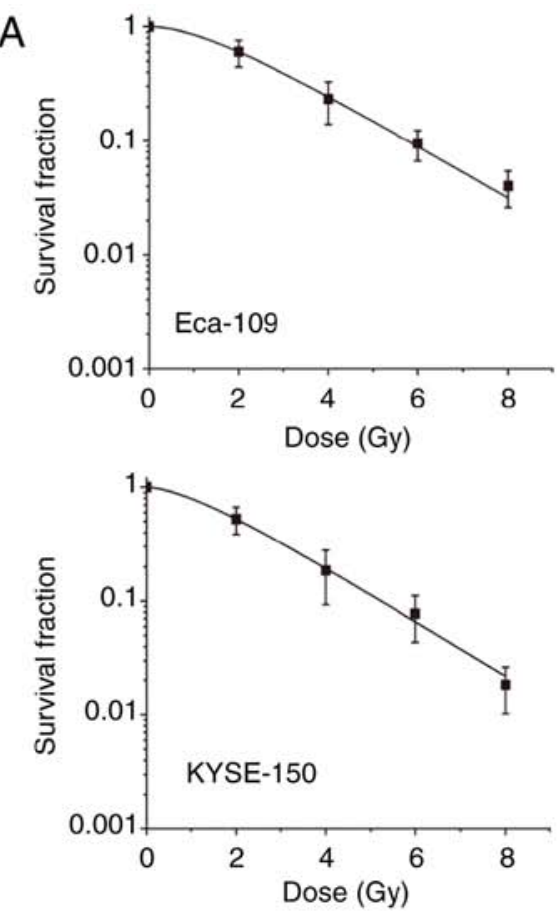

B
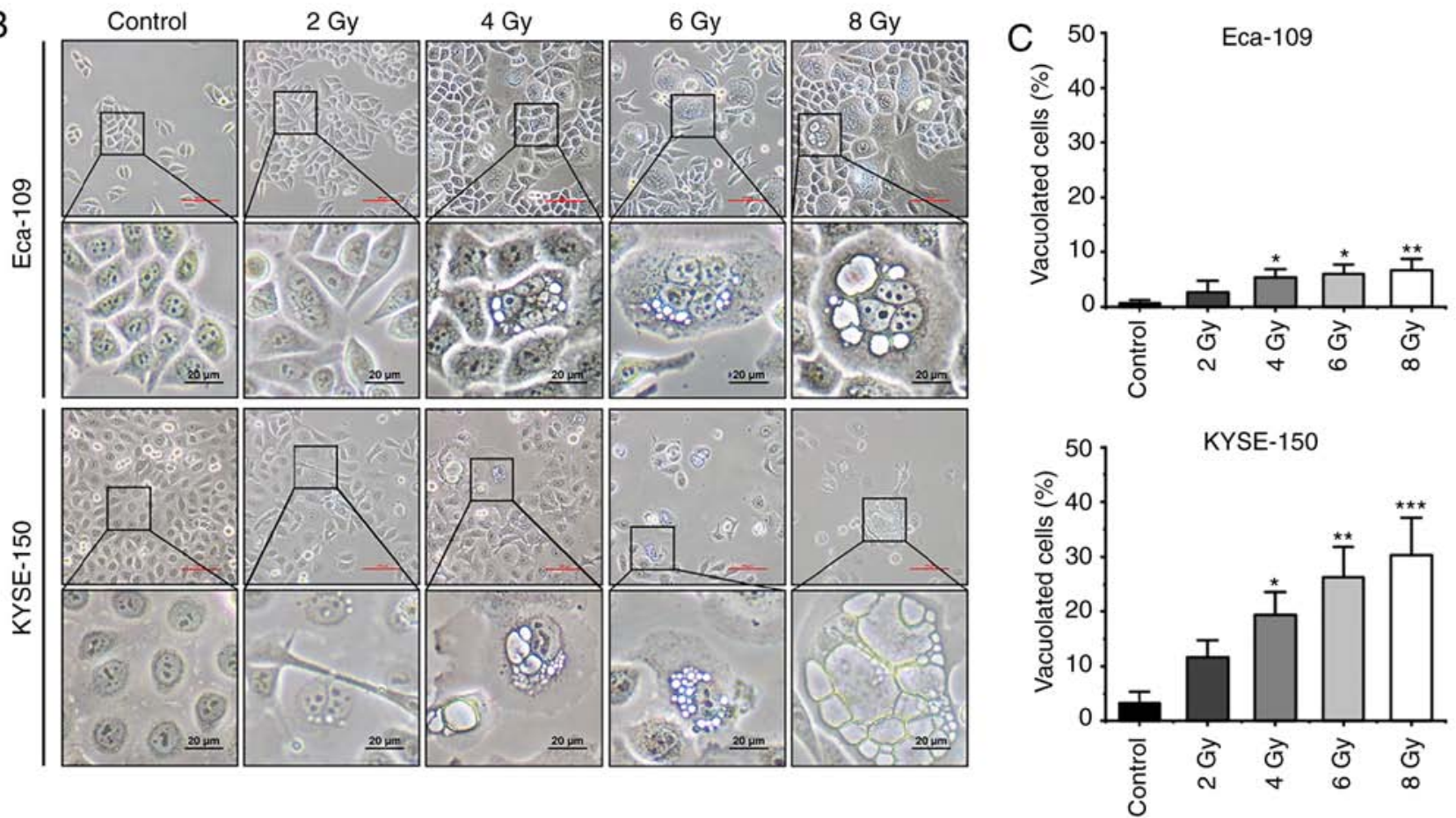

Figure 1. ${ }^{125} \mathrm{I}$ seed radiation results in reduced cell proliferation and morphological changes in Eca-109 and KYSE-150 cells. Cells were exposed to 2, 4, 6 or 8 Gy radiation. (A) Dose-survival curves of Eca-109 and KYSE-150 cells following ${ }^{125}$ I seed irradiation were fitted using a multi-target single-hit model. Scale bar (red), $100 \mu \mathrm{m}$. (B) Morphological changes of Eca-109 and KYSE-150 cells were observed under a light microscope. (C) The percentage of vacuolated cells was measured under a light microscope. ${ }^{*} \mathrm{P}<0.05,{ }^{* *} \mathrm{P}<0.01,{ }^{* * *} \mathrm{P}<0.001$ vs. control group. ${ }^{125} \mathrm{I}$, Iodine- 125 .

${ }^{125}$ I seed radiation induces DNA damage and G2/M cell cycle arrest. Radiation-induced DNA damage serves an important role in the anti-cancer effects of ${ }^{125}$ I seed radiation. Histone $\mathrm{H} 2 \mathrm{AX}$ localizes to the site of DNA double stranded breaks, where it is phosphorylated to $\gamma$-H2AX. The phosphorylated $\gamma$-H2AX further recruits DNA damage repair factors to repair the damaged DNA double strands (31). For the purpose of investigating cellular DNA damage and repair, nuclear $\gamma-\mathrm{H} 2 \mathrm{AX}$ foci and the protein expression levels of $\gamma$-H2AX were observed
$48 \mathrm{~h}$ after irradiation (Fig. 2A and B). The results suggested that ${ }^{125} \mathrm{I}$ seed radiation significantly induced DNA damage and repair in both Eca-109 and KYSE-150 cells, even at a low cumulative dose of $2 \mathrm{~Gy}$. Progression of the cell cycle is delayed until the damaged DNA is repaired (31), thus cell cycle distribution was assessed (Fig. 2C). As shown in Fig. 2D, ${ }^{125}$ I seed radiation significantly increased the proportion of cells in the $\mathrm{G} 2 / \mathrm{M}$ phase and decreased the proportion of cells in the G0/G1 phase, in a dose-dependent manner. Furthermore, the degree 
A
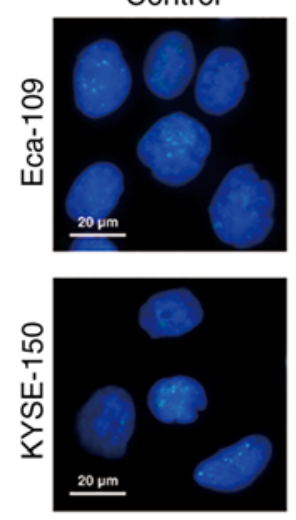

B
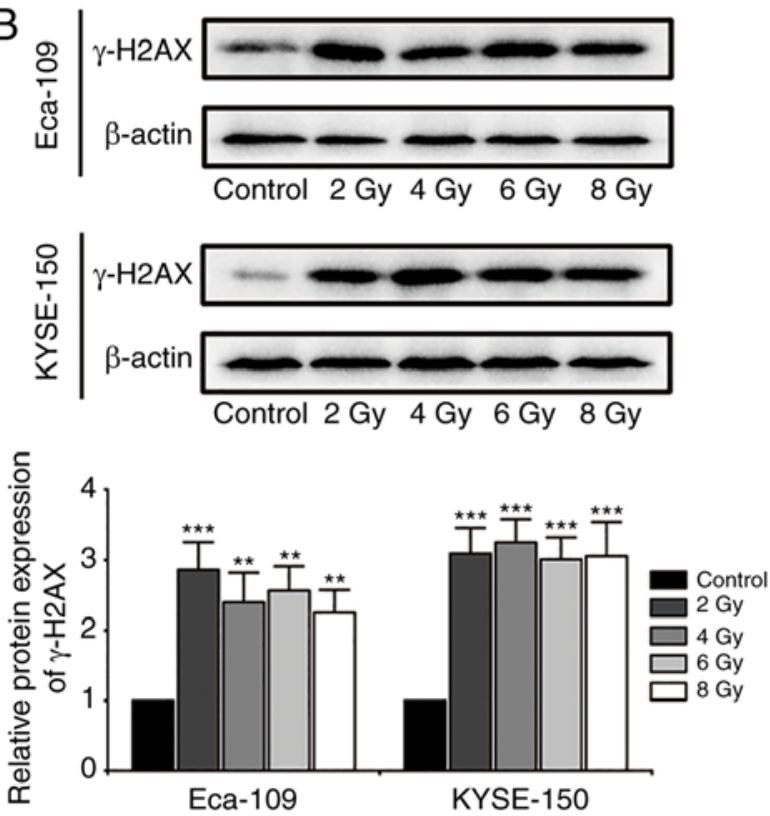

C

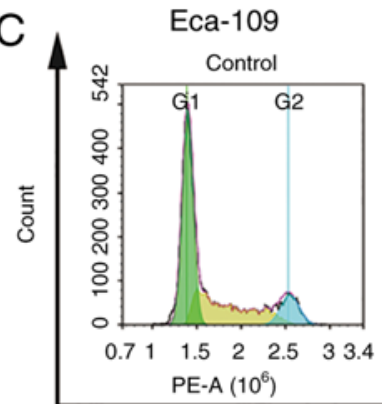

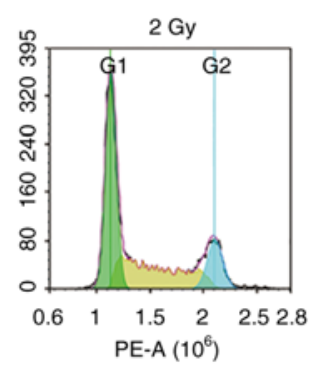

PE-A $\left(10^{6}\right)$

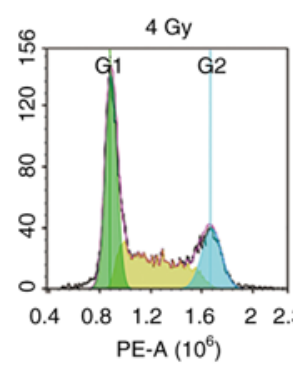

$\mathrm{Pl}$
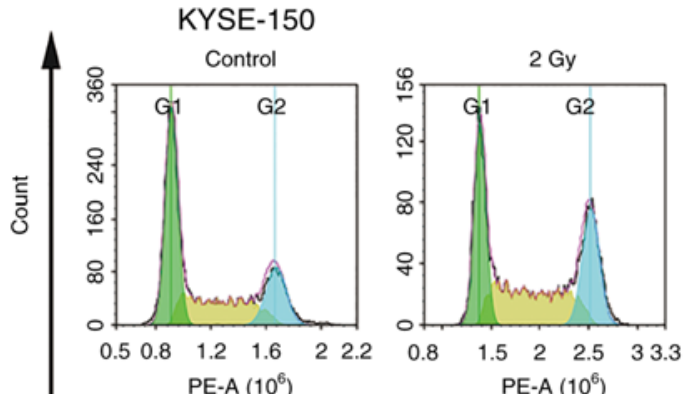

PE-A $\left(10^{6}\right)$
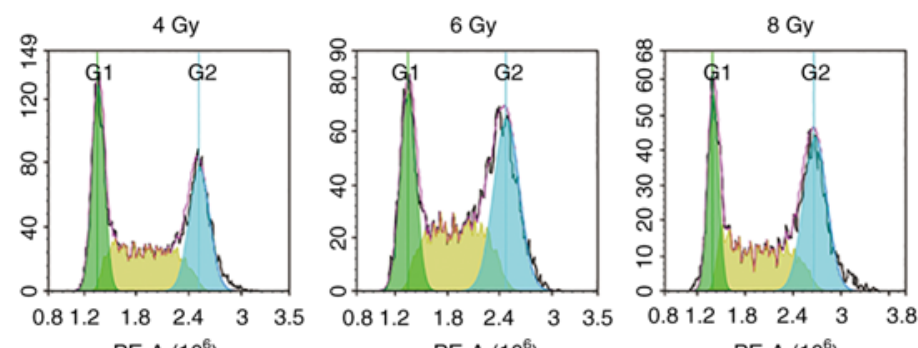

$\mathrm{PI}$
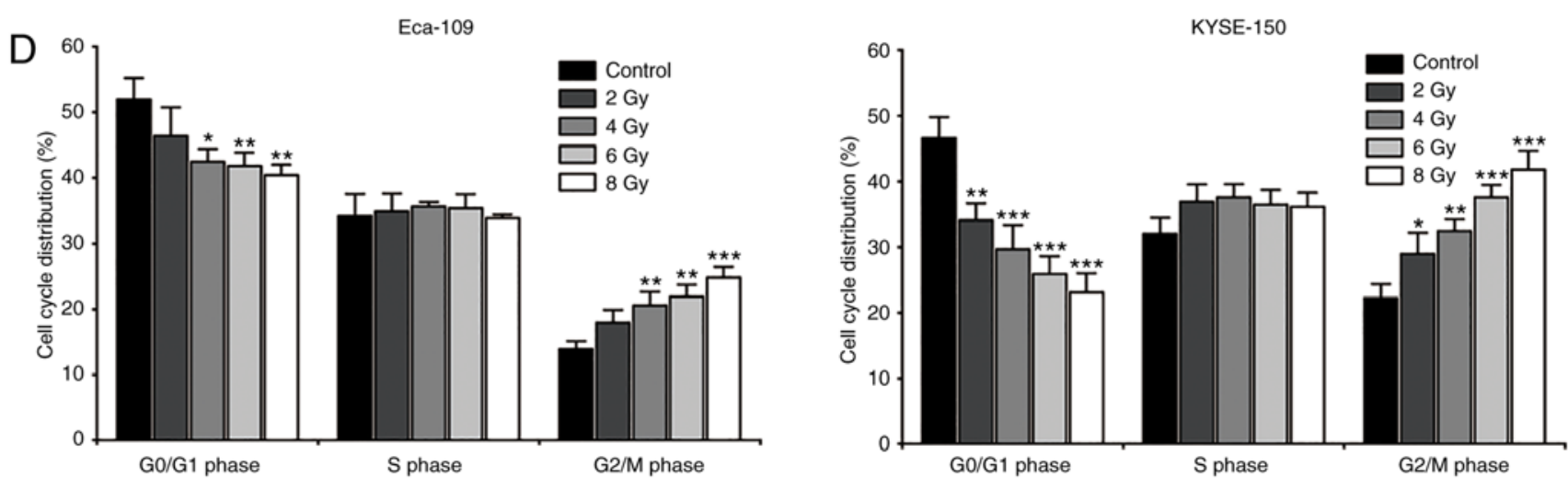

Figure 2. DNA damage repair and cell cycle arrest in Eca-109 and KYSE-150 cells following ${ }^{125}$ I seed irradiation. Cells were exposed to 2, 4,6 and 8 Gy radiation. (A) After $48 \mathrm{~h}$ of culture following $4 \mathrm{~Gy}$ irradiation, formation of $\gamma-\mathrm{H} 2 \mathrm{AX}$ foci (green) was examined under the fluorescence microscope; the nuclei were stained with DAPI (blue). (B) Protein expression levels of $\gamma$-H2AX $48 \mathrm{~h}$ after irradiation was determined by western blot. $\beta$-actin was used as the loading control. (C and D) Cell cycle distribution of Eca-109 and KYSE-150 cells was quantitatively analyzed using flow cytometry. ${ }^{*} \mathrm{P}<0.05,{ }^{* *} \mathrm{P}<0.01,{ }^{* * *} \mathrm{P}<0.001$ vs. control group. ${ }^{125}$ I, Iodine-125; PI, propidium iodide; PE-A, phycoerythrin-Area. 

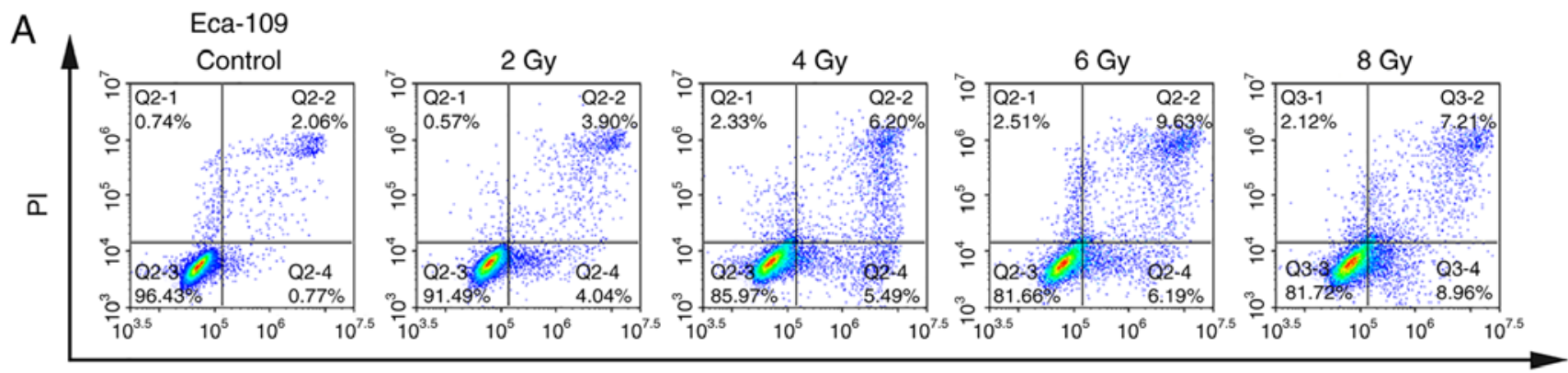

Annexin V-EGFP
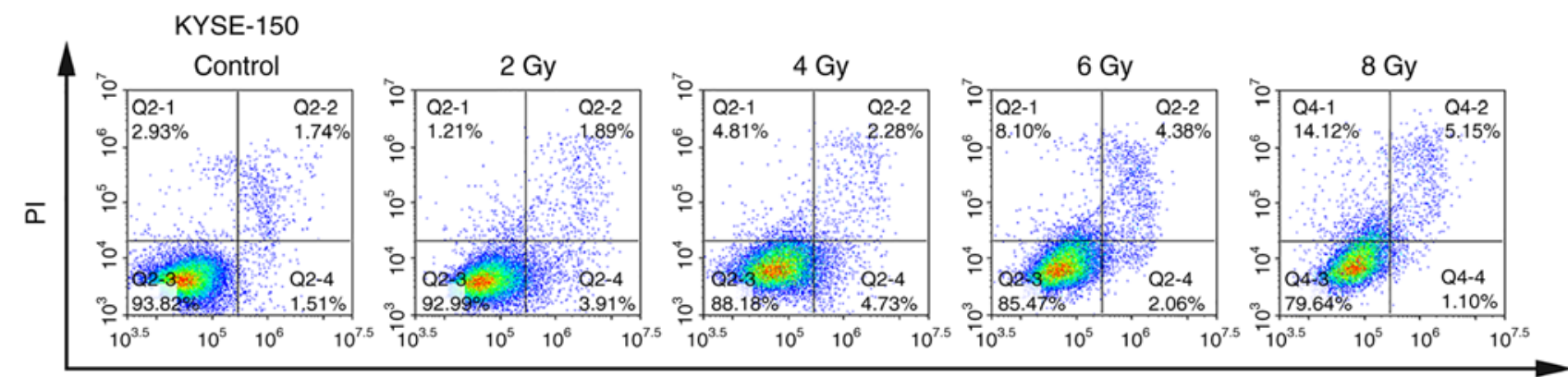

Annexin V-EGFP
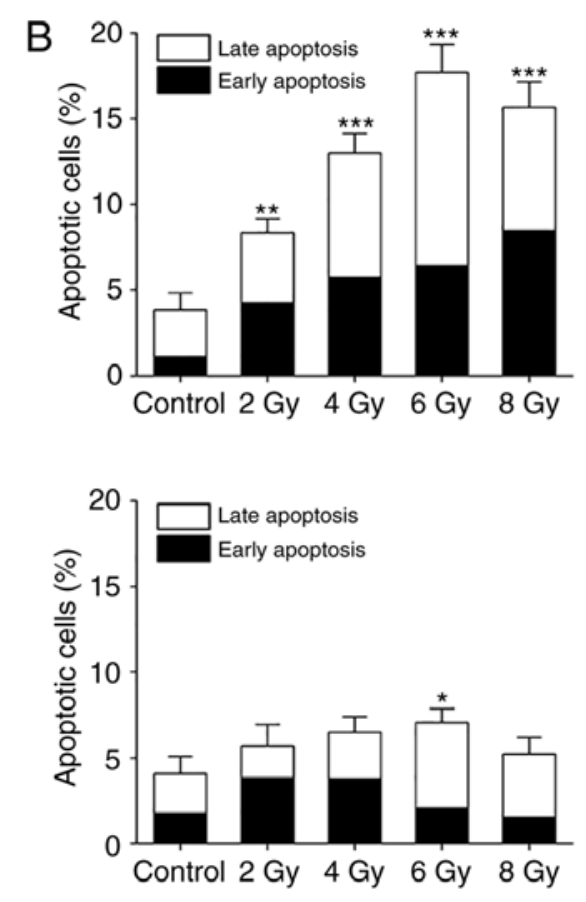

C
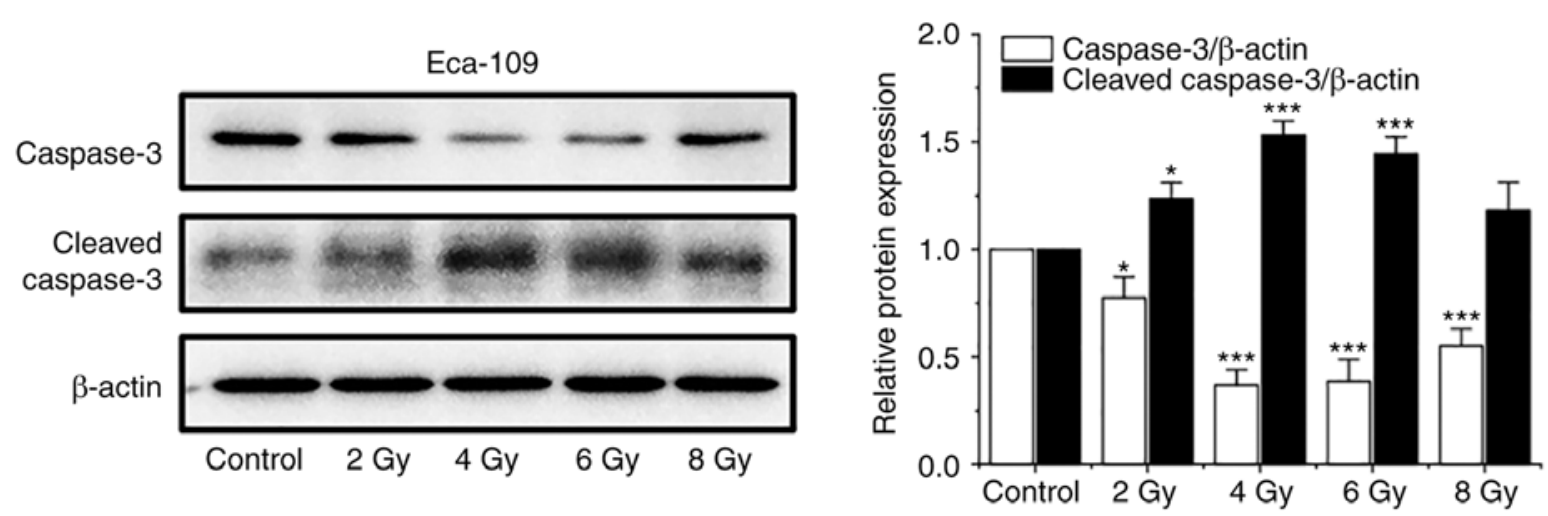

Figure 3. ${ }^{125}$ I seed radiation induces apoptosis in Eca-109 and KYSE-150 cells. Cells were exposed to 2, 4, 6 or 8 Gy radiation. (A and B) Apoptosis of Eca-109 and KYSE-150 cells was detected using Annexin V-EGFP/PI and quantitatively analyzed using flow cytometry. (C) Relative protein expression levels of caspase- 3 and cleaved caspase- 3 were analyzed by western blot. $\beta$-actin was used as a loading control. 
D

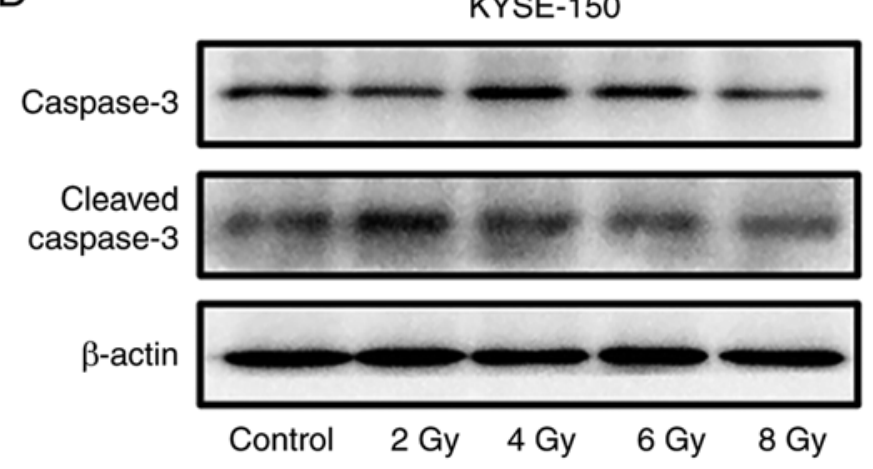

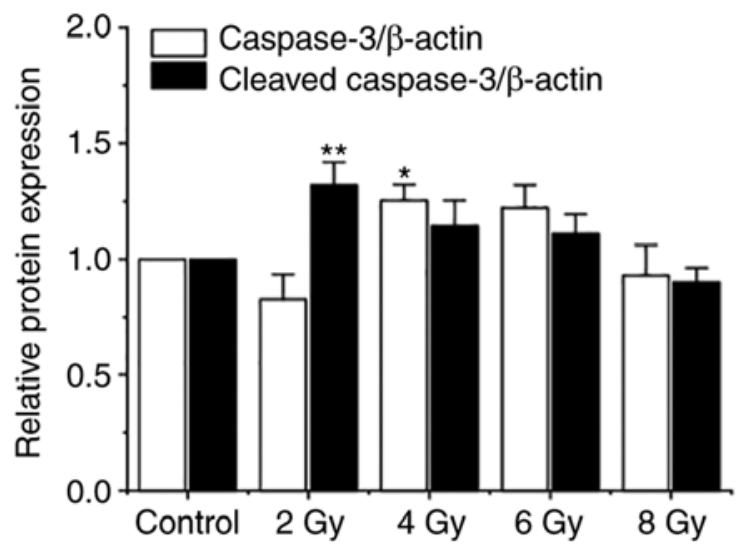

Figure 3. Continued. (D) Relative protein expression levels of caspase-3 and cleaved caspase-3 were analyzed by western blot. $\beta$-actin was used as a loading control. ${ }^{*} \mathrm{P}<0.05,{ }^{* *} \mathrm{P}<0.01,{ }^{* * *} \mathrm{P}<0.001$ vs. control group. ${ }^{125}$ I, Iodine-125; EGFP, enhanced green fluorescent protein; PI, propidium iodide.

of $\mathrm{G} 2 / \mathrm{M}$ cell cycle arrest following irradiation was higher in KYSE-150 cells compared with the Eca-109 cells.

${ }^{125}$ I seed radiation induces apoptosis and non-apoptotic cell death in KYSE-150 cells. In previous studies, apoptosis was considered the major mode of cell death induced by ${ }^{125} \mathrm{I}$ seed radiation in various types of cancer cells $(8,13,14)$. An annexin V/PI assay was used to investigate apoptosis induced by ${ }^{125} \mathrm{I}$ seed radiation in both cell lines. As shown in Fig. 3A and B, the apoptotic rates of Eca-109 and KYSE-150 cells increased as the cumulative dose increased, peaking at $6 \mathrm{~Gy}$ and declining at 8 Gy. The apoptotic rates of KYSE-150 cells were relatively low compared with the Eca-109 cells. The maximum apoptotic rate was $7.07 \pm 0.81 \%$ for KYSE- 150 cells and $17.70 \pm 1.61 \%$ for Eca-109 cells $(\mathrm{P}=0.001)$. However, the proportion of necrotic cells (EGFP-/PI+) in KESY-150 cells increased along with the increase in cumulative dose. These results suggest that apoptosis is not the major mode of cell death induced by ${ }^{125} \mathrm{I}$ seed radiation in KESY-150 cells. To assess caspase activation, the levels of caspase- 3 and cleaved caspase- 3 were determined by western blot analysis. In Eca-109 cells, increase in cleavage of caspase-3 was consistent with the results obtained from the Annexin V/PI assay (Fig. 3C). In the KYSE-150 cells, caspase-3 cleavage was observed with 2 Gy radiation, and the levels decreased at higher doses (Fig. 3D). These results suggest that cell death induced by ${ }^{125}$ I seed radiation in Eca-109 cells was primarily through caspase-dependent apoptosis, whereas in KYSE-150 cells, both apoptosis and non-apoptotic (primary) modes were responsible.

${ }^{125}$ I seed radiation induces protective autophagy in Eca-109 and KYSE-150 cells. Autophagy is characterized by the formation of autophagosomes and autolysosomes, which manifest as cytoplasmic vacuoles (27). In the present study, extensive cytoplasmic vacuoles were observed following irradiation, particularly in KYSE-150 cells (Fig. 1B and C). Therefore, whether ${ }^{125}$ I seed radiation induced autophagy in Eca-109 and KYSE-150 cells was further investigated. During autophagy, LC3-I is converted to LC3-II through lipidation, thus the levels of LC3, and the ratio of LC3-II to LC3-I are frequently used as indicators of autophagy $(20,24,32)$. A total of $48 \mathrm{~h}$ after $6 \mathrm{~Gy}$ irradiation, the cells were stained with an anti-LC3 antibody and observed under a fluorescent microscope. As shown in Fig. 4A, the number of LC3 punctuations per cell increased notably following irradiation. Subsequently, western blot analysis was performed to determine the ratio of LC3-II to LC3-I in cells following exposure to 2, 4, 6 or 8 Gy radiation. The ratio of LC3-II to LC3-I in cells increased significantly at $4 \mathrm{~Gy}$ in both cell lines, and then is decreased slightly in Eca-109 cells at higher does, but maintained in KYSE-150 cells (Fig. 4B). Theoretically, the increased levels of LC3-II may have been the result of augmented formation of autophagosomes or impaired maturation of autophagosomes, which can block the degradation of LC3-II (24). To determine autophagic degradation activity, the protein levels of p62, a ubiquitin-binding protein which is selectively degraded in autolysosomes (18), was analyzed by western blot analysis. The levels of p62 decreased in both cell lines following irradiation (Fig. 4B), suggesting that ${ }^{125} \mathrm{I}$ seed radiation induced autophagic flux in Eca-109 and KYSE-150 cells.

To further investigate the roles of autophagy in cell death induced by ${ }^{125} \mathrm{I}$ seed radiation, the effect of 3-MA, an autophagy inhibitor, were assessed. Given that the apoptotic rates of both cell lines peaked at $6 \mathrm{~Gy}$, the cells were pretreated with $0.5 \mathrm{mM} 3-\mathrm{MA}$ for $2 \mathrm{~h}$ and then exposed to $6 \mathrm{~Gy}$ radiation. Western blot analysis demonstrated that the ratios of LC3-II to LC3-I decreased following 3-MA treatment in both cell lines (Fig. 4C), suggesting that 3-MA attenuated ${ }^{125}$ I seed radiation-induced autophagy. Annexin V/PI assay demonstrated that 3-MA improved ${ }^{125}$ I seed radiation-induced apoptosis in both cell lines (Fig. 4D). Given the higher degree of non-apoptotic cell death in KYSE-150 cells, cell viability was assessed in these cells. As shown in Fig. 4E, 3-MA further decreased cell viability of irradiated Eca-109 and KYSE-150 cells, but did not affect the cell viability of unirradiated cells. These results suggest that in Eca-109 and KYSE-150 cells, autophagy serves a protective role in ${ }^{125}$ I seed radiation-induced cell death.

3-MA did not reduce the percentage of vacuolated cells in both irradiated and unirradiated cells (Fig. 4F). Additionally, immunofluorescence images stained with an anti-LC3 antibody showed that certain vacuoles did not co-localize with the LC3 punctuations (Fig. 5A), suggesting that these vacuoles did not originate from autophagosome/autolysosomes. These findings demonstrate that autophagy is not wholly responsible for cytoplasmic vacuolation in either cell line following ${ }^{125} \mathrm{I}$ seed irradiation. 
A
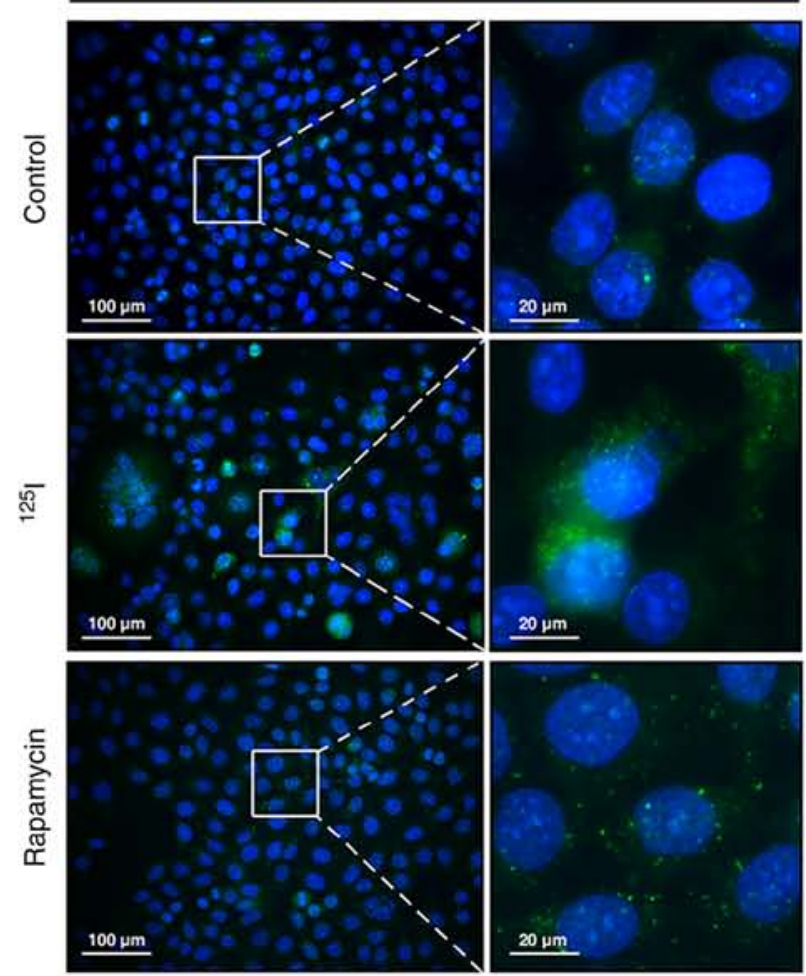

B
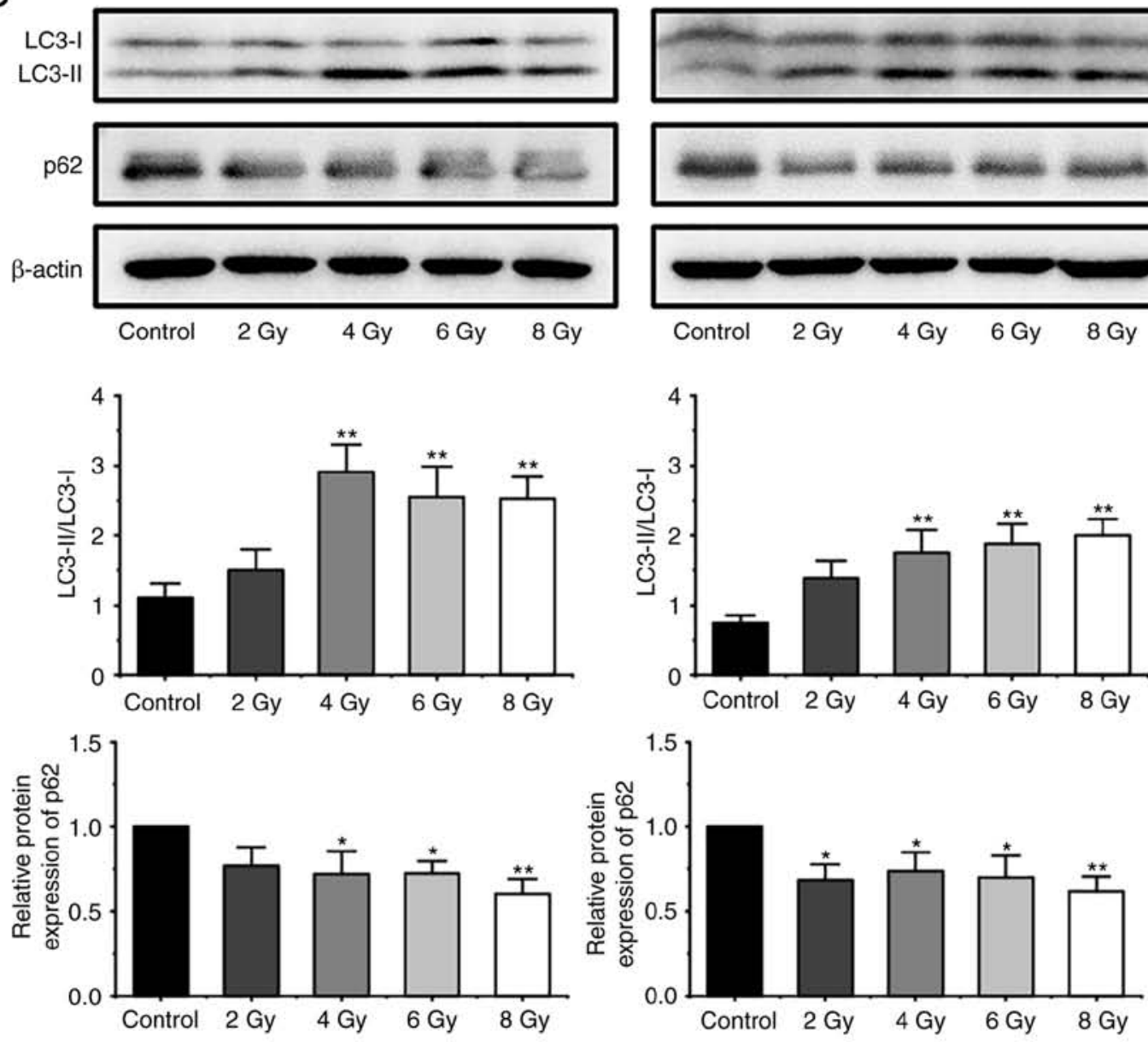

Figure 4. ${ }^{125}$ I seed radiation induces protective autophagy in Eca-109 and KYSE-150 cells. (A) Following 6 Gy irradiation, and 48 h of culture, LC3 punctuation (green) was detected using a fluorescent microscope. Nuclei were stained with DAPI (blue). Cells treated with $200 \mathrm{nM}$ rapamycin overnight were used as the positive control. (B) Cells were exposed to 2, 4, 6 or 8 Gy radiation. The ratios of LC3-II to LC3-I expression, and the relative protein expression of p62 were analyzed by western blot. $\beta$-actin was used as a loading control. Cells were pretreated with or without 3-MA, 2 h prior to 6 Gy irradiation. 

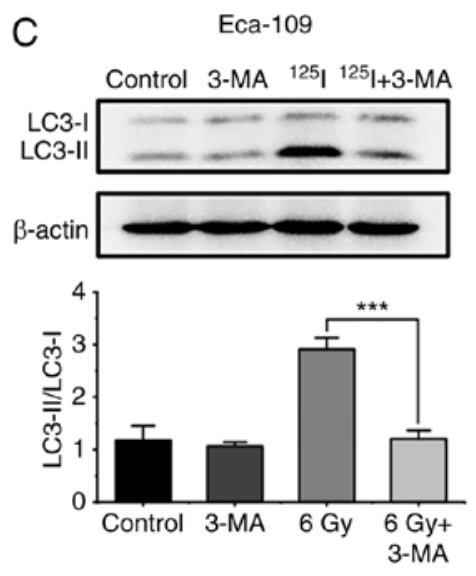

KYSE-150
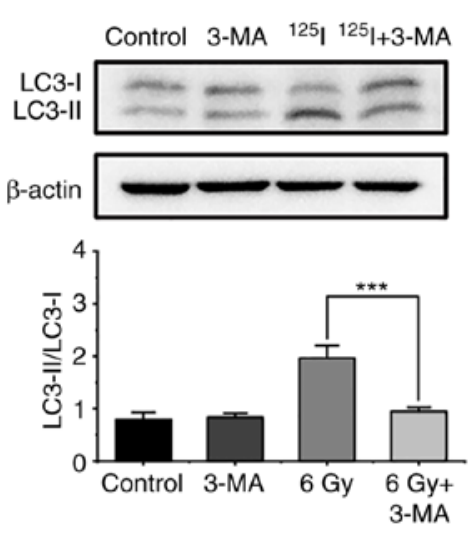

$\mathrm{D}$

$\bar{\alpha}$

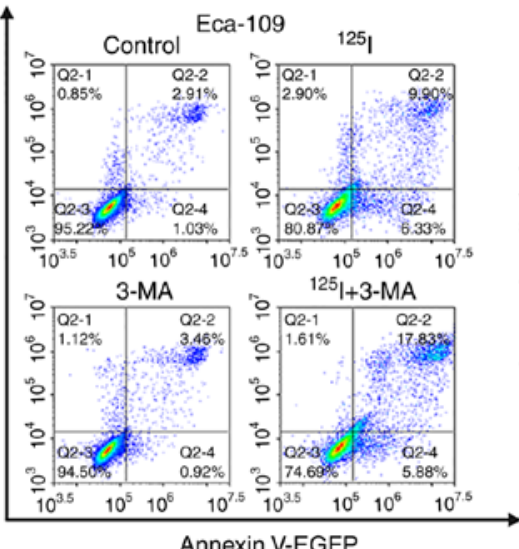

KYSE-150
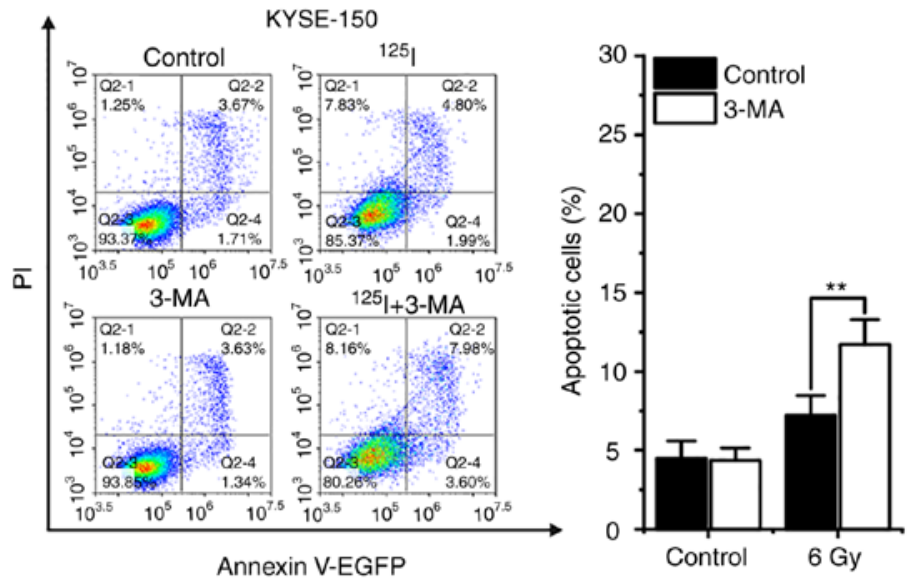
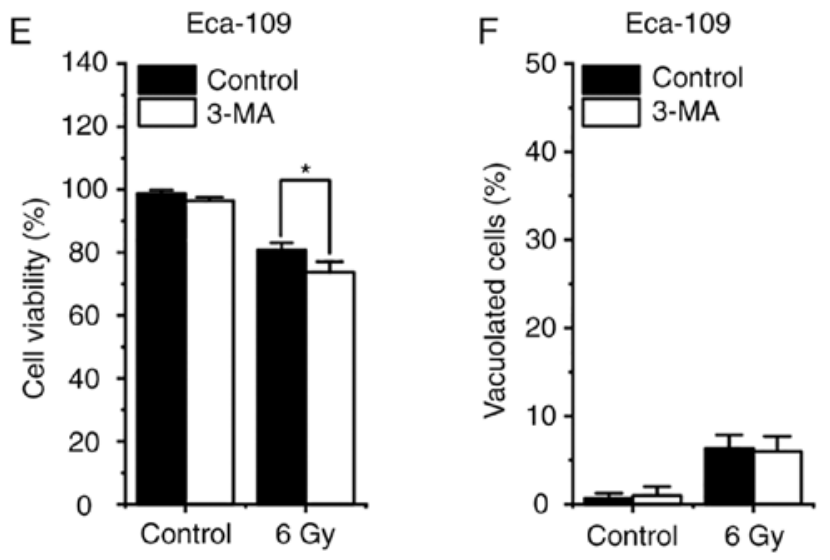

KYSE-150
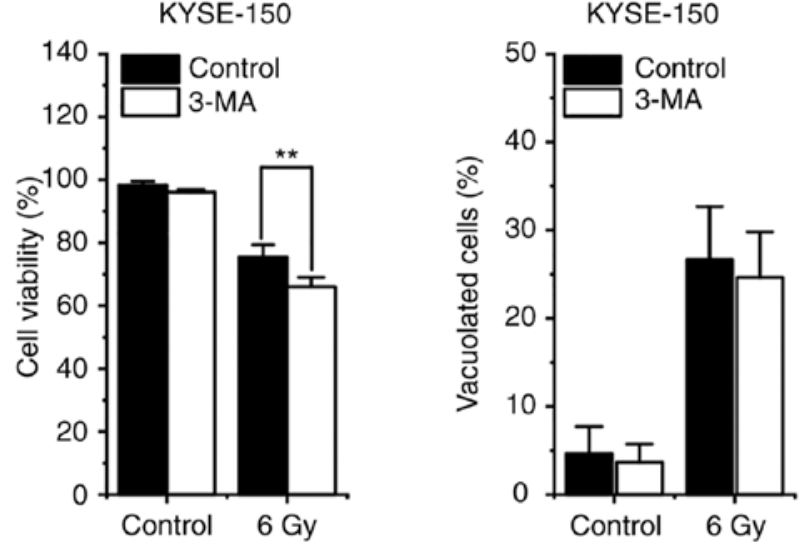

Figure 4. Continued. After $48 \mathrm{~h}$ of the indicated treatment, (C) the ratios of LC3-II to LC3-I were determined by western blot, and (D) apoptosis was analyzed by Annexin V-EGFP/PI assay using flow cytometry. (E) The percentage of cells with trypan blue exclusion, and (F) the percentage of vacuolated cells were measured under a light microscope. ${ }^{*} \mathrm{P}<0.05,{ }^{* * *} \mathrm{P}<0.01,{ }^{* * * *} \mathrm{P}<0.001$ vs. control group. ${ }^{125}$ I, Iodine-125; 3-MA, 3-methyladenine; EGFP, enhanced green fluorescent protein; PI, propidium iodide. 
A

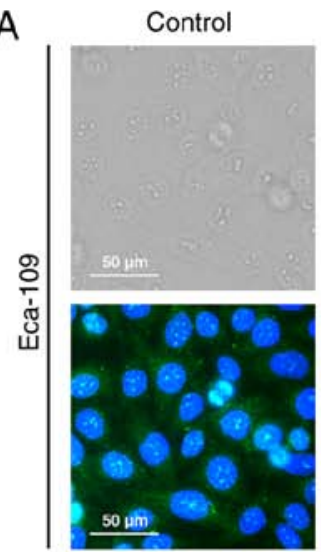

125

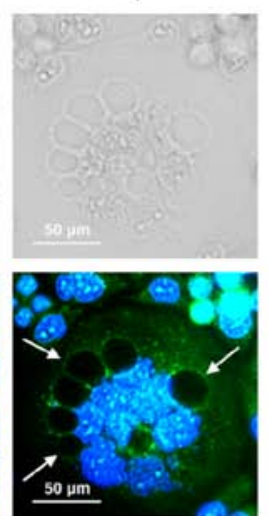

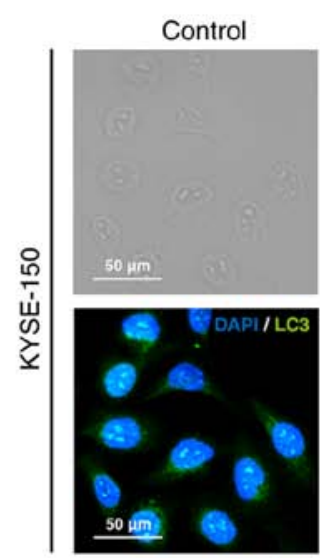

125

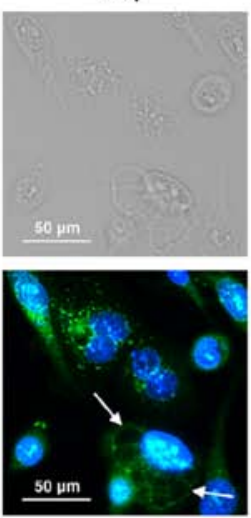

B
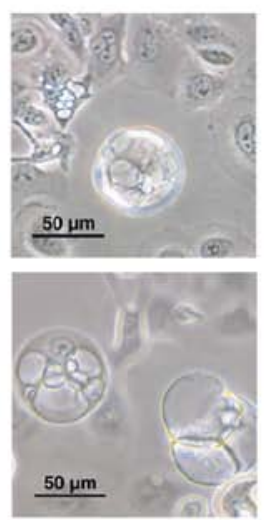

125
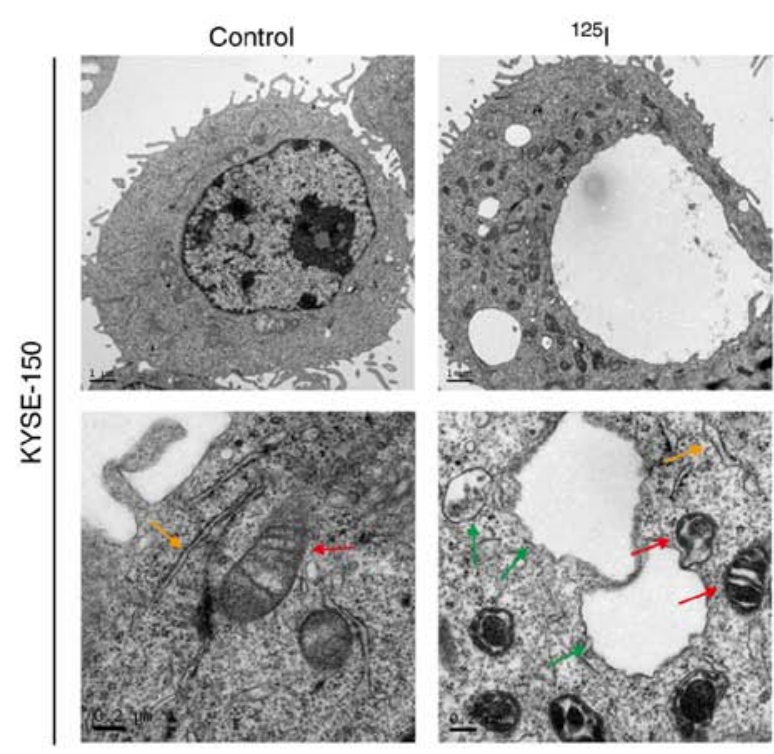

C
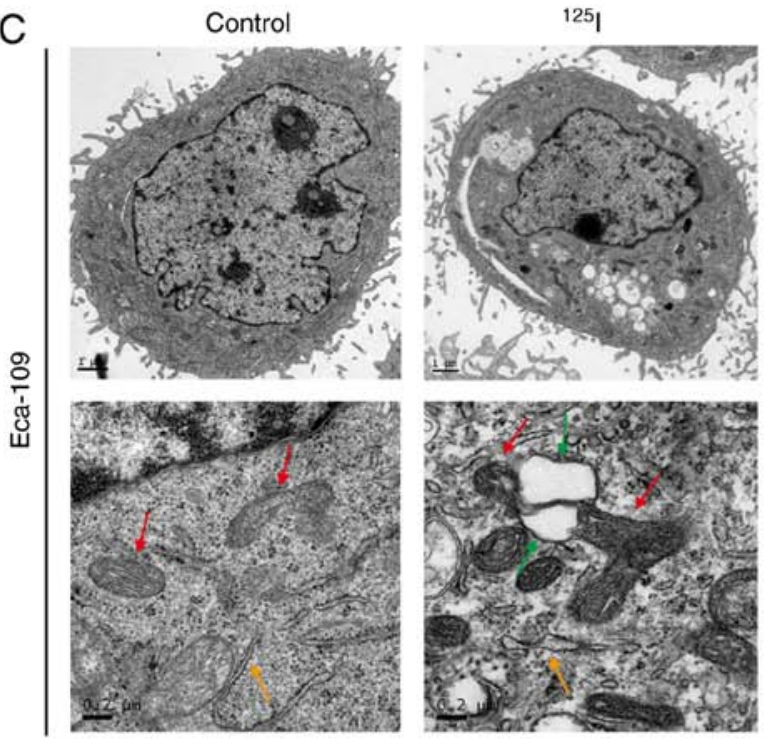

D
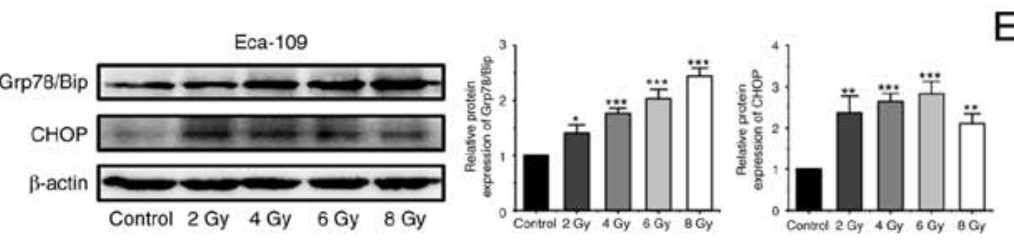

$E$
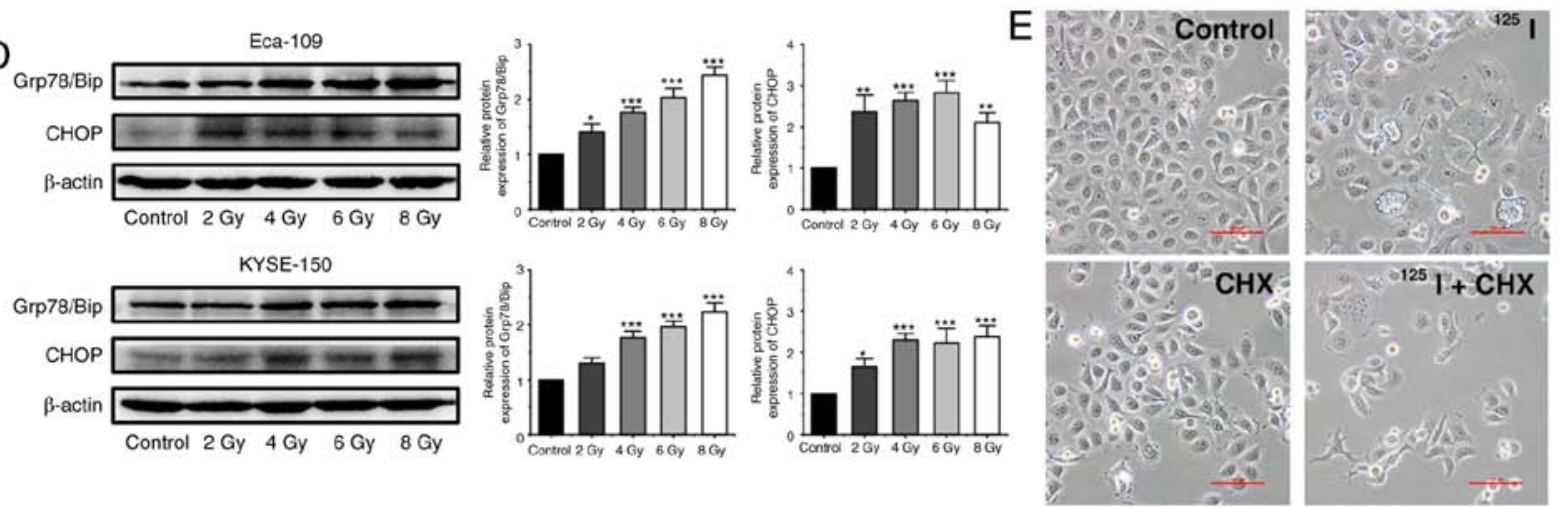

Figure 5. ${ }^{125}$ I seed radiation induces paraptosis in Eca-109 and KYSE-150 cells. (A) Following irradiation, LC3 punctuation (green) was detected under a fluorescence microscope; the nuclei were stained with DAPI (blue). Certain vacuolar membranes appeared negative for anti-LC3 antibody (white arrow). (B) Cell morphology of detached KYSE-150 cells was observed under the light microscope following 4 Gy irradiation. (C) Ultrastructure of Eca-109 and KYSE-150 cells was observed using transmission electron microscopy. Swollen mitochondria (red arrow), endoplasmic reticulum (orange arrow) and vacuoles (green arrow) were observed. (D) Levels of ER stress markers, Grp78/Bip and CHOP, were determined by western blotting. $\beta$-actin was used as a loading control. (E) KYSE-150 cells were pretreated with or without CHX, $2 \mathrm{~h}$ before $4 \mathrm{~Gy}$ irradiation. Morphological changes of KYSE-150 cells were examined under a light microscope. Scale bar, $100 \mu \mathrm{m} .{ }^{*} \mathrm{P}<0.05,{ }^{* *} \mathrm{P}<0.01,{ }^{* * *} \mathrm{P}<0.001$ vs. control group. ${ }^{125}$ I, Iodine-125; CHX, cycloheximide.

${ }^{125}$ I seed radiation induces paraptosis and ER stress in KYSE-150 and Eca-109 cells. Paraptosis results in cytoplasmic vacuolation, and the number and size of vacuoles increase over time during paraptosis $(21,26)$. In the irradiated KYSE-150 cells, the cytoplasmic vacuoles enlarged in size gradually, the nuclei were located peripherally, and subsequently, death-associated cellular detachment occurred (Fig. 5B). To a lesser degree, similar phenomena were also observed in irradiated Eca-109 cells, particularly in MNGCs (Fig. 1B). Therefore, the ultrastructure of mitochondria and ER by TEM were observed. Compared with the unirradiated controls, irradiated cells exhibited swollen mitochondria and ER, and 

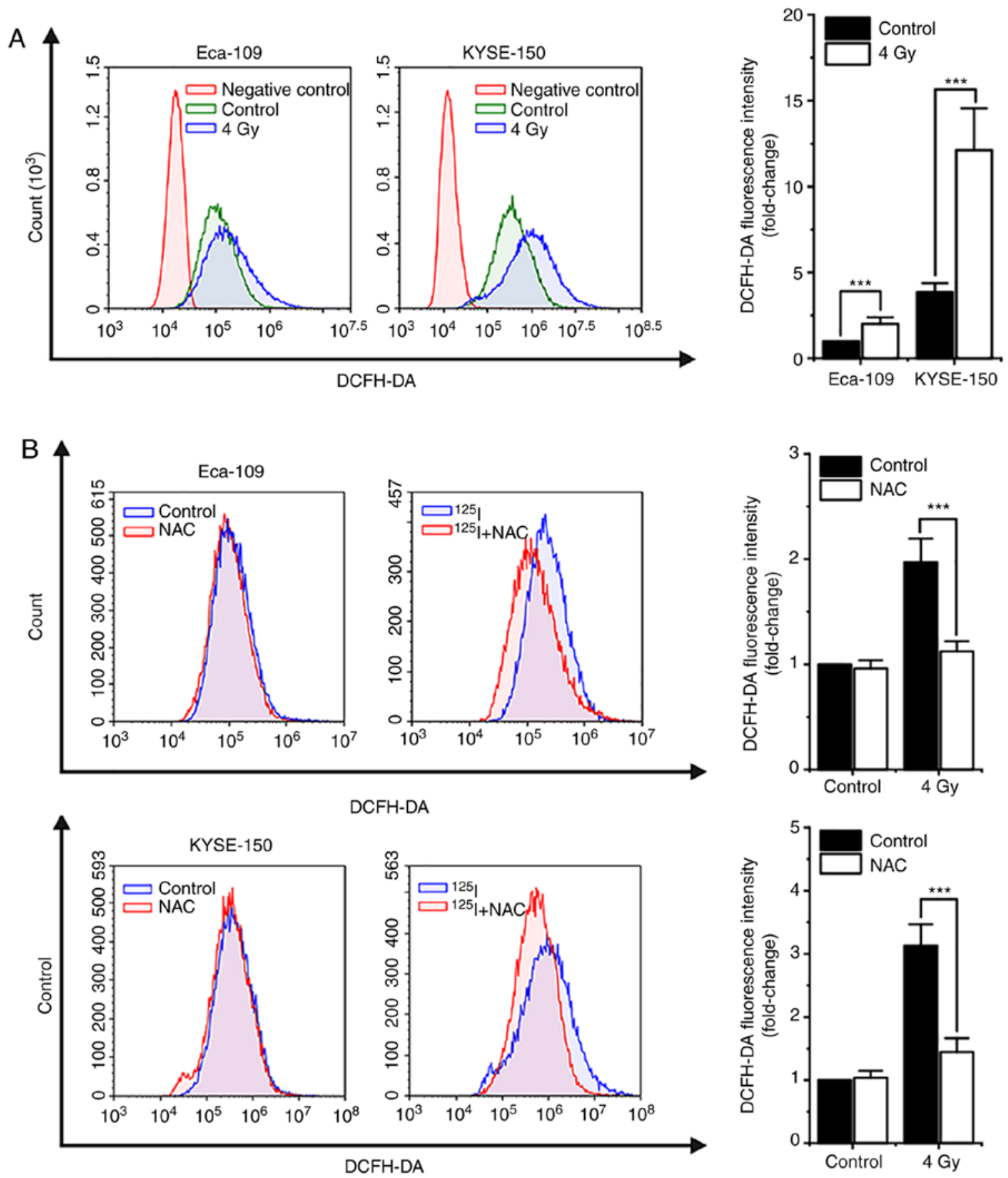

C
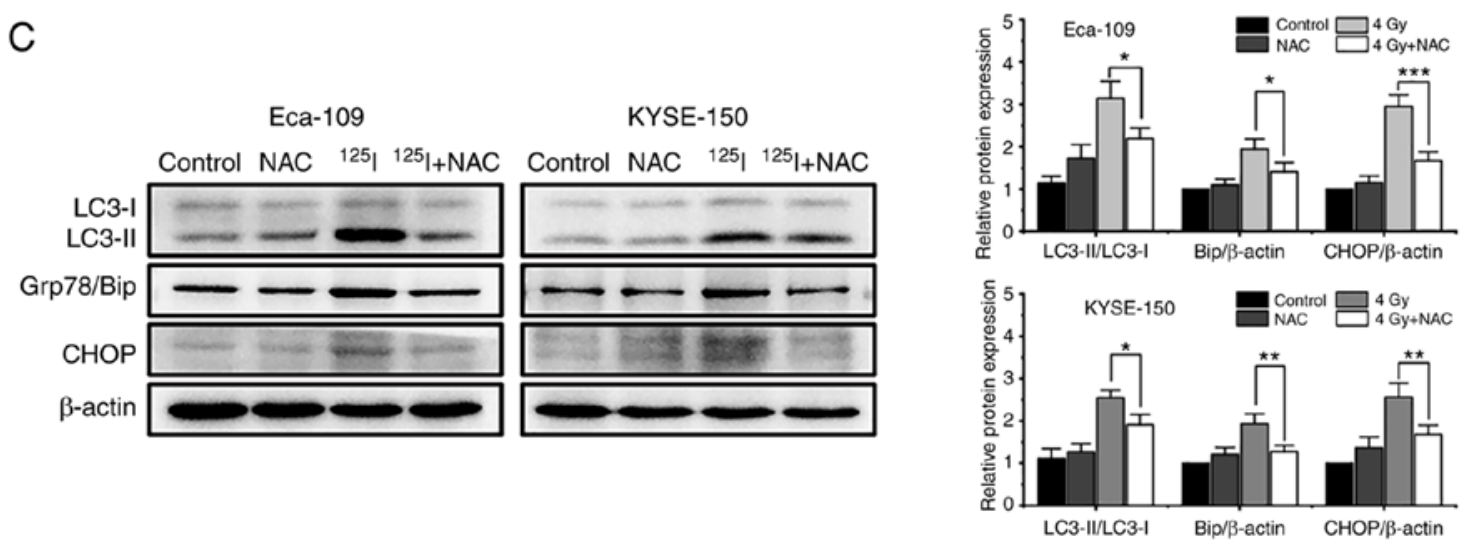

Figure 6. ${ }^{125}$ I seed radiation-induced production of ROS is critical for apoptosis, autophagy and paraptosis in Eca-109 and KYSE-150 cells. Cells were pretreated with or without NAC $4 \mathrm{~h}$ prior to 4 Gy irradiation. (A and B) Cells were labeled with DCFH-DA probe, the intracellular ROS levels were quantitatively analyzed calculating the mean fluorescence intensity using flow cytometry. Unlabeled cells were used as the negative control. (C) Protein expression levels of LC3-I, LC3-II, Grp78/Bip and CHOP, were determined by western blot. $\beta$-actin was used as the loading control. 

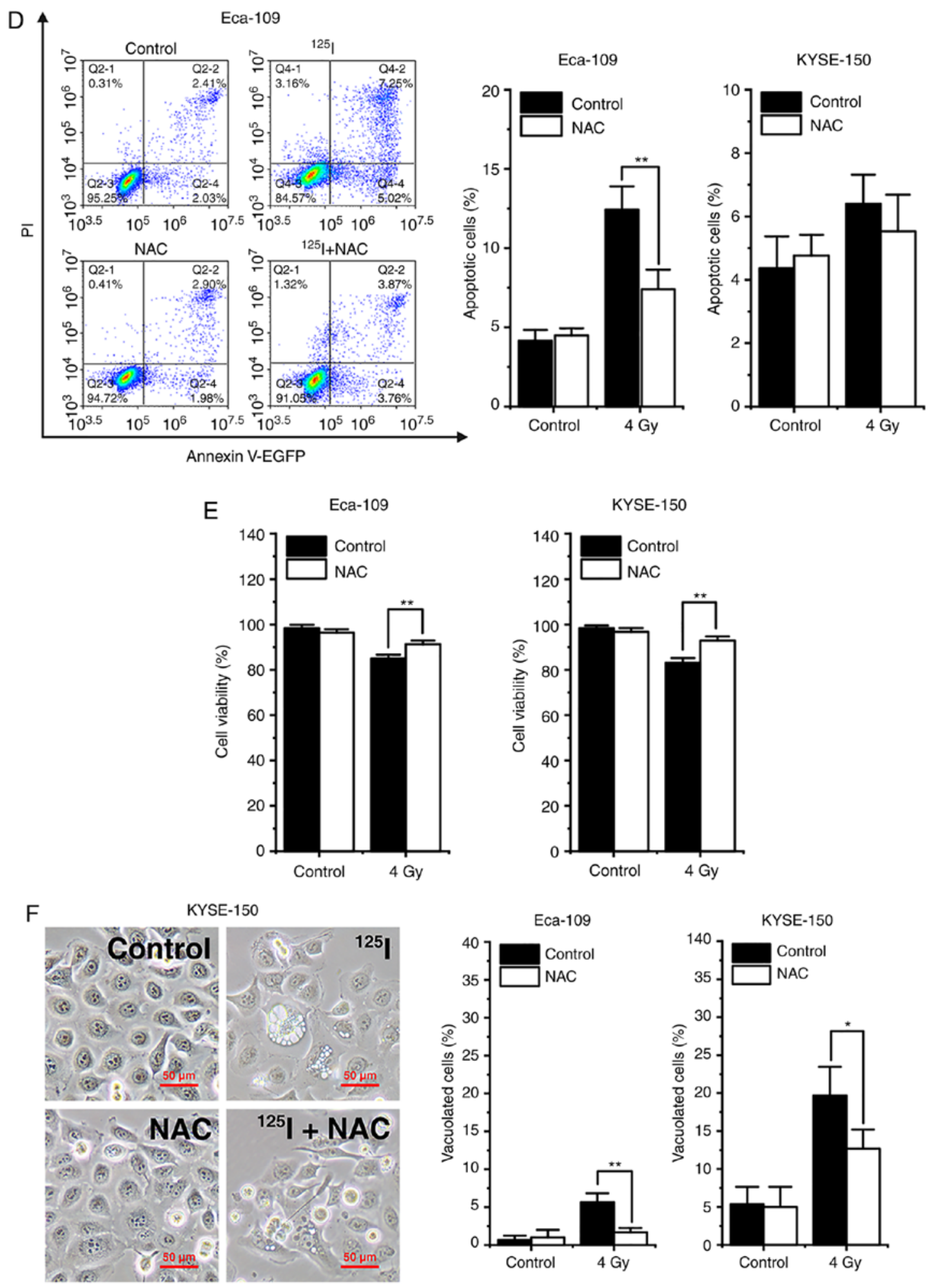

Figure 6. Continued. (D) Apoptosis was detected by Annexin V-EGFP/PI assay and quantitatively analyzed using flow cytometry. (E) Percentage of cells with trypan blue excluded was measured under a light microscope. (F) Morphological changes of cells were observed, and the percentage of vacuolated cells was measured under a light microscope. ${ }^{*} \mathrm{P}<0.05,{ }^{* * *} \mathrm{P}<0.01,{ }^{* * *} \mathrm{P}<0.001$ vs. control group. ${ }^{125} \mathrm{I}$, Iodine-125; ROS, reactive oxygen species; NAC, N-acetyl-L-cysteine; DCFH-DA, 2',7'-dichlorodihydrofluorescein diacetate; EGFP, enhanced green fluorescent protein; PI, propidium iodide.

also consequent vacuolation in both cell lines (Fig. 5C). Given that ER vacuolization is typically associated with persistent ER stress (33), ER stress was assessed by measuring the protein expression levels of the ER stress markers, Grp78/Bip and CHOP. Elevated levels of Grp78/Bip and CHOP were detected in both Eca-109 and KYSE-150 cells following irradiation, and persistent elevation of CHOP was observed in KYSE-150 cells (Fig. 5D). Studies have shown that de novo protein synthesis is required for cytoplasmic vacuolation in paraptosis, and CHX, a protein synthesis inhibitor, inhibits paraptosis (21). Therefore, KYSE-150 cells were pre-treated with $\mathrm{CHX}(2 \mu \mathrm{M})$ for $2 \mathrm{~h}$ prior to $4 \mathrm{~Gy}$ irradiation. The results showed that CHX effectively 
attenuated cytoplasmic vacuolation in irradiated cells (Fig. 5E). Taken together, these results suggest that paraptosis is a key mechanism of cell death induced by ${ }^{125}$ I seed radiation in KYSE-150 cells, and paraptosis is partially responsible for ${ }^{125} \mathrm{I}$ seed radiation induced cell death in Eca-109 cells.

${ }^{125}$ I seed radiation-induced increases in ROS levels serve an important role in apoptosis, autophagy and paraptosis. It has been reported that oxidative stress induced by single high-dose radiation results in apoptosis and autophagy (17). Thus, the effects of ROS on cell death induced by ${ }^{125} \mathrm{I}$ seed radiation were assessed. Firstly, $48 \mathrm{~h}$ after $4 \mathrm{~Gy}$ irradiation, the cells were labeled with the intracellular ROS probe, DCFH-DA, and analyzed by flow cytometry. The results showed that ${ }^{125}$ I seed radiation increased the levels of intracellular ROS in both Eca-109 and KYSE-150 cells. KYSE-150 cells had higher basal levels of ROS compared with Eca-109 cells $(\mathrm{P}<0.001)$. The increase in ROS levels were more prominent in KYSE-150 cells compared with Eca-109 cells (fold change, $3.13 \pm 0.34$ vs. $2.00 \pm 0.39$, respectively, $\mathrm{P}=0.020$; Fig. 6A). Subsequently, cells were pretreated with 5 mM NAC, an ROS scavenger, $4 \mathrm{~h}$ prior to $4 \mathrm{~Gy}$ irradiation. The results showed that NAC reduced the accumulation of intracellular ROS induced by ${ }^{125}$ I seed radiation in both cell lines (Fig. 6B). Western blot analysis demonstrated that NAC decreased the levels of the autophagy indicator, the ratio of LC3-II to LC3-I, and ER stress markers, Grp78/Bip and CHOP, in irradiated Eca-109 and KYSE-150 cells (Fig. 6C). Furthermore, as shown in Fig. 6D, NAC attenuated ${ }^{125} \mathrm{I}$ seed radiation-induced apoptosis in Eca-109 cells $(\mathrm{P}=0.002)$, but did not significantly attenuate apoptosis in KYSE-150 cells $(\mathrm{P}=0.695)$. As ${ }^{125} \mathrm{I}$ seed radiation killed KYSE-150 cells primarily through paraptosis, the changes in cell viability and cytoplasmic vacuolation were assessed. The results showed that NAC attenuated ${ }^{125} \mathrm{I}$ seed radiation-induced decreases in cell viability in both cell lines (Fig. 6E). Furthermore, for both irradiated cell lines, the percentage of vacuolated cells decreased significantly following NAC treatment (Fig. 6F). Taken together, these results suggest that ${ }^{125} \mathrm{I}$ seed radiation-induced increases in ROS levels are critical for autophagy, apoptosis and paraptosis in Eca-109 and KYSE-150 cells.

${ }^{125}$ I seed radiation inhibits ESCC xenograft growth in vivo. The in vivo effects of ${ }^{125} \mathrm{I}$ seed radiation using both Eca-109 and KYSE-150 human ESCC xenograft mouse models were assessed. The ${ }^{125} \mathrm{I}$ seed was implanted into the tumor mass of each mouse, which received continuous low-dose-rate irradiation for 15 days with a cumulative dose of $\sim 20 \mathrm{~Gy}$. Tumor growth was significantly reduced after 9 days of ${ }^{125}$ I seed irradiation (Fig. 7A), and the weights and volumes of harvested tumors were significantly lower in the ${ }^{125} \mathrm{I}$ seed group compared with the control group (Fig. 7B and C). To evaluate oxidative stress in vivo, the levels of ROS were measured by staining the tissue with DCFH-DA. Increased levels of ROS were observed in the ${ }^{125}$ I seed group (Fig. 7D). H\&E staining showed cellular vacuolation was present in tissue sections obtained from the irradiated tumor mass (Fig. 7E). Furthermore, ${ }^{125} \mathrm{I}$ seed radiation resulted in apoptosis (TUNEL assay, Fig. 7F) and reduced proliferation (immunohistochemistry for Ki-67, Fig. 7G) in irradiated tumor tissues. The results show that ${ }^{125} \mathrm{I}$ seed radiation induced ROS generation and DNA damage, initiated cell apoptosis and vacuolation-related cell death (potentially via paraptosis), and reduced cell proliferation and tumor growth in vivo.

\section{Discussion}

${ }^{125}$ I seed brachytherapy was first used for the treatment of prostate cancer in the 1970s (34). Because of its high efficacy and low complication rate, ${ }^{125}$ I seed radiation was eventually used for treatment of various unresectable and/or locally recurrent types of cancer, including malignant glioma (5), non-small cell lung cancer (35) and esophageal cancer (11). Multiple studies demonstrated that, compared with EBRT, ${ }^{125}$ I seed brachytherapy has greater RBE values, suggesting that cancer cells are more sensitive to ${ }^{125}$ I seed radiation $(8,9,36)$. However, the mechanisms underlying the effects of ${ }^{125}$ I seed radiation are not completely understood. In the present study, the anti-cancer mechanisms of ${ }^{125}$ I seed radiation in ESCC cells (Eca-109 and KYSE-150) were assessed. To the best of our knowledge, this is the first report describing the roles of apoptosis, autophagy and paraptosis in ESCC cells following ${ }^{125}$ I seed irradiation.

Previous studies have attributed the anti-cancer effects of ${ }^{125}$ I seed radiation to DNA damage, G2/M cell cycle arrest and apoptosis $(8,14,37,38)$. DNA damage can be induced directly by radiation or indirectly by radiation-induced ROS (22). Cell cycle checkpoints function to protect cells by delaying the progression of the cell cycle until damaged DNA is repaired (31). For cells with irreparable DNA damage, the cell death pathway, primarily intrinsic caspase-dependent apoptosis, is activated (22). In the present study, to reasonably compare our data with previous studies, cells were cultured for $48 \mathrm{~h}$ following treatment $(8,13,14) .{ }^{125} \mathrm{I}$ seed radiation induced significant DNA damage and cell cycle arrest at the G2/M phase in both cell lines; however, the mode of cell death and the prominence of each mode differed in each cell line. In Eca-109 cells, ${ }^{125}$ I seed radiation resulted in noticeable caspase-dependent apoptosis, and the changes in the tendency of apoptosis was almost consistent with the data reported in studies on other types of cancer cells $(8,14)$. In KYSE-150 cells, ${ }^{125}$ I seed radiation initiated both apoptotic and non-apoptotic cell death. As the level of apoptosis was too low to exert a noticeable effect on cell death, it was hypothesized that non-apoptotic modes were the primary mode of cell death in KYSE-150 cells following ${ }^{125}$ I seed irradiation.

Instead of the typical apoptotic morphology, extensive cytoplasmic vacuolation was observed in KYSE-150 cells, particularly at a cumulative dose of $\geq 4 \mathrm{~Gy}$. Cytoplasmic vacuolation is usually accompanied by autophagy and/or paraptosis. The vacuoles associated with autophagy are derived from double-membraned autophagosome and autolysosomes (27). The autophagosome sequesters damaged cytoplasmic material, and then fuses with the lysosome to form an autolysosome, where the cytoplasmic material is degraded. This dynamic process is termed autophagic flux (18). In the present study, autophagic flux was assessed by measuring the expression levels of the autophagy-related proteins, LC3 and p62. The results supported the notion ${ }^{125} \mathrm{I}$ seed radiation initiated autophagic flux in both Eca-109 and KYSE-150 cells. As excessive autophagy results in ACD, it 

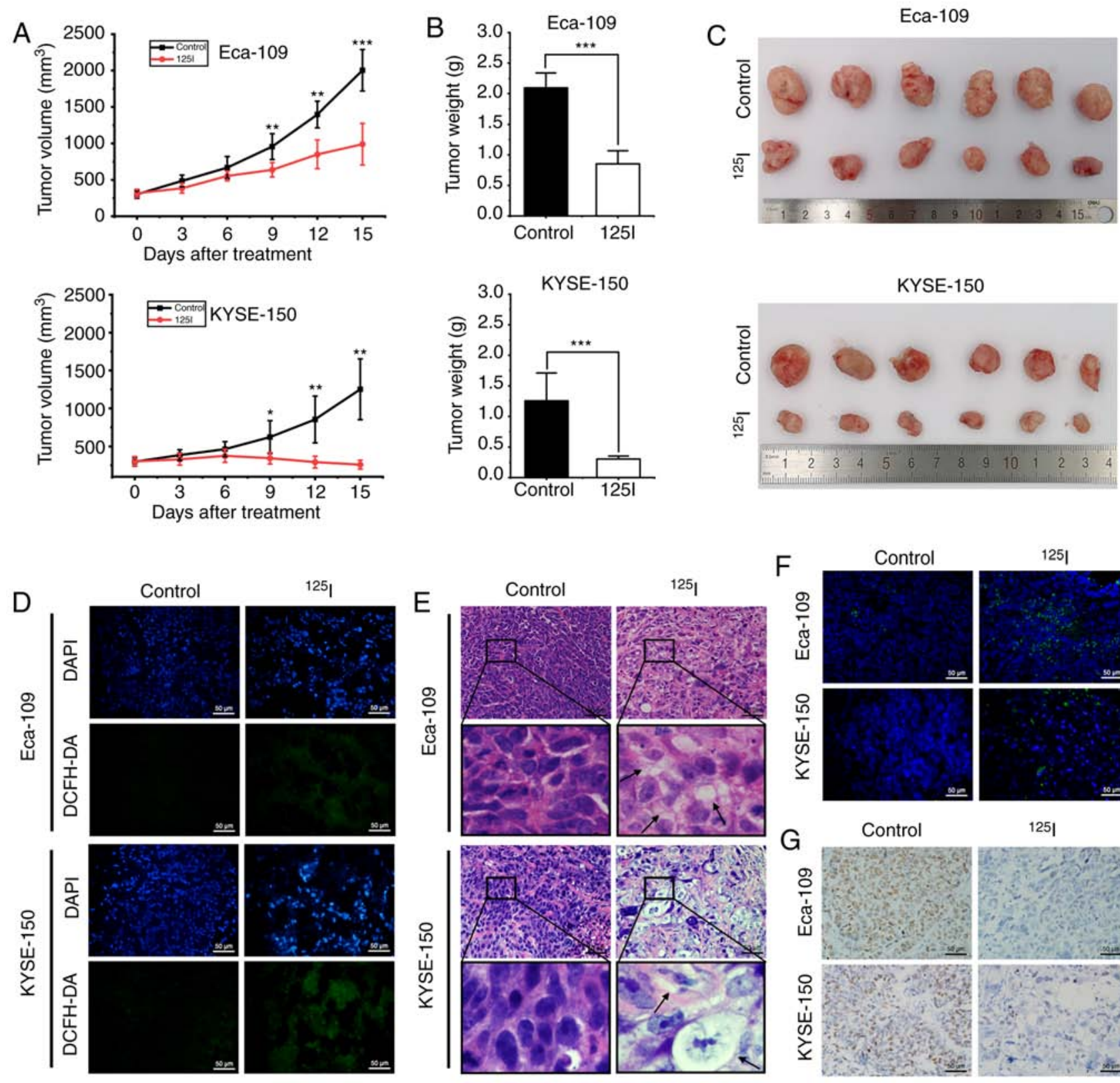
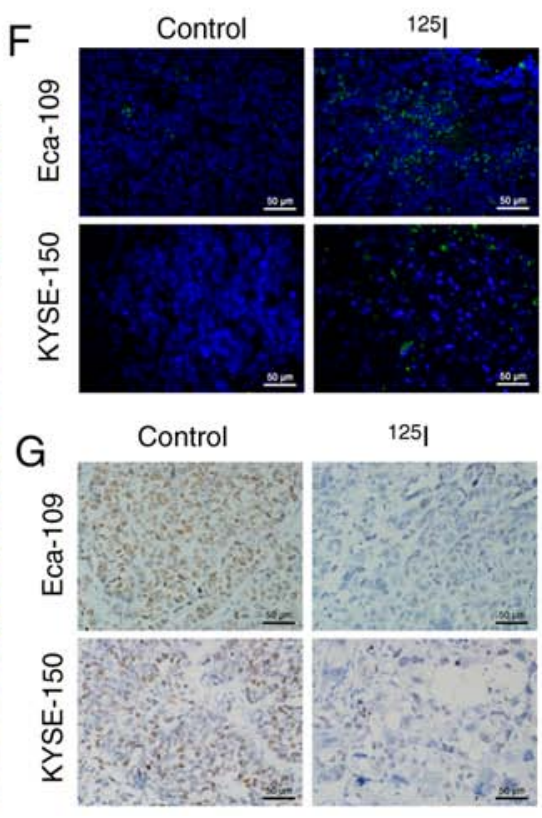

125

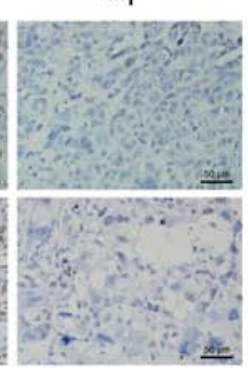

Figure 7. ${ }^{125}$ I seed radiation inhibits growth of Eca-109 and KYSE-150 esophageal cancer xenografts in mice. (A) Mice received tumor puncture (control group) or ${ }^{125}$ I seed implantation ( ${ }^{125} \mathrm{I}$ seed group) when the average tumor volume reached $300 \mathrm{~mm}^{3}$. Tumor volumes were measured every three days for 15 days after treatment. (B) Weight of harvested tumors was measured 15 days after treatment. (C) Representative images of the harvested tumors. (D) Immunofluorescence detection of ROS using DCFH-DA staining (green). Tissues were counterstained with DAPI (blue). Scale bar, $50 \mu \mathrm{m}$. (E) Representative hematoxylin and eosin staining of harvested tumor specimens. Cytoplasmic vacuolation (black arrows) was observed after ${ }^{125} \mathrm{I}$ seed implantation. Scale bar, $50 \mu \mathrm{m}$. (F) Representative TUNEL staining of harvested tumor specimens. Scale bar, $50 \mu \mathrm{m}$. (G) Representative immunohistochemistry staining of the proliferation marker, Ki-67 in harvested tumor specimen. Scale bar, $50 \mu \mathrm{m}$. ${ }^{*} \mathrm{P}<0.05,{ }^{* *} \mathrm{P}<0.01,{ }^{* * * *} \mathrm{P}<0.001$ vs. control group. ${ }^{125} \mathrm{I}$, Iodine-125; ROS, reactive oxygen species; DCFH-DA, 2',7'-dichlorodihydrofluorescein diacetate.

was determined whether the non-apoptotic cell death mode observed in KYSE-150 cells was ACD. However, our data show that autophagy inhibition increased cell apoptosis and reduced cell viability in irradiated cells, indicating that ${ }^{125} \mathrm{I}$ seed radiation induces pro-survival autophagy in both cell lines. These results are consistent with previous studies showing that EBRT induces protective autophagy, and inhibition of autophagy by 3-MA enhances the radiosensitivity of Eca-109 cells $(19,32)$. These data also suggest that autophagy inhibition may be a potentially effective anti-cancer therapeutic strategy in ${ }^{125}$ I seed brachytherapy.
Autophagy inhibition by 3-MA did not reduce the percentage of vacuolated cells, suggesting that paraptosis occurred in the majority of the vacuolated cells. As a type of PCD, paraptosis appears to differ from that of apoptosis, autophagy and necrosis. Also, paraptosis is insensitive to apoptotic and autophagic inhibitors (24). Furthermore, paraptosis may be an effective cell-killing mode for cells with impaired apoptotic mechanisms $(39,40)$. The molecular mechanism of paraptosis is not yet fully understood, and there is hitherto no specific biochemical assay for paraptosis $(27,41)$. In the present study, paraptosis was confirmed 
primarily through its characteristics (42): Extensive and intense cytoplasmic vacuolation, fused from the swollen ER and/or mitochondria; correlation with ER stress; and de novo protein synthesis. The results of the present study suggest that ${ }^{125} \mathrm{I}$ seed radiation prominently initiates paraptosis in KYSE-150 cells, which is the primary mode of cell death induced by ${ }^{125} \mathrm{I}$ seed radiation. ${ }^{125} \mathrm{I}$ seed radiation mediated cell death is different from that triggered by EBRT, which exhibits typical apoptosis in KYSE-150 cells, and the cells are prone to form apoptosis resistance following fractionated EBRT $(43,44)$. Characteristic morphological changes associated with paraptosis were also observed in Eca-109 cells in vitro and in vivo. In Eca-109 cells, paraptosis was primarily observed in MNGCs, which is a morphological characteristic of mitotic catastrophe (45). Although mitotic catastrophe is regarded as a step preceding cell death (46), a large proportion of MNGCs still remain viable and exhibit DNA synthesis following EBRT $(45,47)$. The results of the present study showed that, in Eca-109 cells, paraptosis was at least partially responsible for cell death induced by ${ }^{125}$ I seed radiation, and may be important for cell death following mitotic catastrophe. In line with previous studies $(8,14)$, the results of the present study also showed that caspase-dependent apoptosis decreased at a cumulative dose of $>6 \mathrm{~Gy}$, suggesting that the remaining cancer cells had improved apoptosis resistance, and for these cells, paraptosis may have been the primary cell-killing mechanism. Hu et al (16) previously demonstrated that ${ }^{125} \mathrm{I}$ seed radiation triggers paraptosis in HCT116 colorectal cancer cells at a dose of $2 \mathrm{~Gy}$. In the present study, the characteristics of paraptosis were not notably present at 2 $\mathrm{Gy}$, and were more prominent at higher doses ( $\geq 4 \mathrm{~Gy}$ ). To the best of our knowledge, paraptosis has not been reported in studies on EBRT. Based on the results of the present study, it may be hypothesized that paraptosis may be associated with the mode of irradiation used as well as the cell type, and this warrants further investigation. The decrease in apoptosis observed at a dose of $>6$ Gy also suggest that combination therapy of ${ }^{125}$ I seed brachytherapy and other treatments such as chemotherapy may be promising, but relevant basic and clinic studies are required.

It is well established that ionizing radiation can induce ROS overproduction in cancer cells $(17,48,49)$. Compared with DNA damage directly induced by ionizing radiation, ROS-induced damage of nucleic acids, proteins and lipids serve more important roles in cell death (50). The majority of studies on ${ }^{125} \mathrm{I}$ seed radiation have only focused on the ROS-mediated DNA damage and consequent apoptosis $(8,14,37)$, whereas over-accumulation of ROS also interferes with various organelles, including the mitochondria and ER, resulting in mitochondrial dysfunction and ER stress response (50). Therefore, it was hypothesized that ${ }^{125}$ I seed radiation-induced autophagy and paraptosis are downstream of ${ }^{125}$ I seed radiation-mediated ROS generation. The results of the present study demonstrated that ${ }^{125} \mathrm{I}$ seed radiation results in a significant increase in ROS levels in both cell lines, and this was significantly reduced by treatment with NAC, a ROS scavenger. Furthermore, NAC attenuated ${ }^{125}$ I seed radiation-induced ER stress, autophagy and reduced cell viability in both cell lines. As the cell death modes were different in the two cell lines, NAC noticeably attenuated ${ }^{125}$ I seed radiation-induced apoptosis in Eca-109 cells and paraptotic changes in KYSE-150 cells. These results suggest that ${ }^{125} \mathrm{I}$ seed radiation-induced apoptosis, autophagy and paraptosis are predominantly mediated by ROS in Eca-109 and KYSE-150 cells.

Apoptosis resistance is an obstacle to successful radiotherapy in patients with advanced ESCC, thus, it would be more effective to treat cancer by initiating cell death through different cell death modes. The results of the present study demonstrated that, in the human ESCC cell lines Eca-109 and KYSE-150, in addition to DNA damage, G2/M cell cycle arrest and apoptosis, ${ }^{125}$ I seed radiation initiated paraptosis, a relatively novel type of PCD. Additionally, ${ }^{125}$ I seed radiation also resulted in the initiation of protective autophagy to attenuate cell death, and ${ }^{125}$ I seed radiation-induced apoptosis, paraptosis and autophagy were predominantly mediated by ROS production in these two ESCC cell lines.

\section{Acknowledgements}

We would like to thank Dr Jian Yang, Dr Yue Chen and Dr Ting-Ting Xu (Jiangsu Key Laboratory of Molecular and Functional Imaging, Southeast University, Nanjing, China) for providing technical assistance.

\section{Funding}

The present study was funded by the National Natural Science Foundation of China (grant no. 81971716) and Jiangsu Provincial Special Program of Social Development (grant no. BE2016783).

\section{Availability of data and material}

The datasets used and/or analyzed during the present study are available from the corresponding author on reasonable request.

\section{Authors' contributions}

JHG, CW and TKL designed the study CW, TKL, CHZ, RF, YW performed the experiments. YW and GYZ analyzed the data. JHG, CW and CHZ drafted the manuscript. All authors contributed to reviewing and revising the manuscript and approved the final version of the manuscript.

\section{Ethics approval and consent to participate}

All experiments involving mice were performed in accordance with the guidelines on animal care and experiments on laboratory animals of the Center of Experimental Animals, Southeast University (Nanjing, China), and were approved by the Animal Experimental Ethics Committee of Southeast University (approval no. 20190225004).

\section{Patient consent for publication}

Not applicable

\section{Competing interests}

The authors declare that they have no competing interests. 


\section{References}

1. Bray F, Ferlay J, Soerjomataram I, Siegel RL, Torre LA and Jemal A: Global cancer statistics 2018: GLOBOCAN estimates of incidence and mortality worldwide for 36 cancers in 185 countries. CA Cancer J Clin 68: 394-424, 2018.

2. Lagergren J, Smyth E, Cunningham D and Lagergren P: Oesophageal cancer. Lancet 390: 2383-2396, 2017.

3. Jatoi A, Martenson JA, Foster NR, McLeod HL, Lair BS, Nichols F, Tschetter LK, Moore DF Jr, Fitch TR and Alberts SR North Central Cancer Treatment Group (N0044): Paclitaxel, carboplatin, 5-fluorouracil, and radiation for locally advanced esophageal cancer: Phase II results of preliminary pharmacologic and molecular efforts to mitigate toxicity and predict outcomes: North central cancer treatment group (N0044). Am J Clin Oncol 30: 507-513, 2007.

4. Tsushima T, Mizusawa J, Sudo K, Honma Y, Kato K, Igaki H, Tsubosa Y, Shinoda M, Nakamura K, Fukuda H, et al: Risk factors for esophageal fistula associated with chemoradiotherapy for locally advanced unresectable esophageal cancer: A supplementary analysis of JCOG0303. Medicine (Baltimore) 95: e3699, 2016

5. Schnell O, Scholler K, Ruge M, Siefert A, Tonn JC and Kreth FW: Surgical resection plus stereotactic 125I brachytherapy in adult patients with eloquently located supratentorial WHO grade II glioma-feasibility and outcome of a combined local treatment concept. J Neurol 255: 1495-1502, 2008.

6. Zhang F, Wang J, Guo J, Li Y, Huang X, Guan Z, Lei G, Wang J, Ye X, Zhao X, et al: Chinese expert consensus workshop report: Guideline for permanent iodine-125 seed implantation of primary and metastatic lung tumors. Thorac Cancer 10: 388-394, 2019.

7. Mo Z, Zhang T, Zhang Y, Xiang Z, Yan H, Zhong Z, Gao F and Zhang F: Feasibility and clinical value of CT-guided (125) I brachytherapy for metastatic soft tissue sarcoma after first-line chemotherapy failure. Eur Radiol 28: 1194-1203, 2018.

8. Zhuang HQ, Wang JJ, Liao AY, Wang JD and Zhao Y: The biological effect of $125 \mathrm{I}$ seed continuous low dose rate irradiation in CL187 cells. J Exp Clin Cancer Res 28: 12, 2009.

9. Wang H, Li J, Qu A, Liu J, Zhao Y and Wang J: The different biological effects of single, fractionated and continuous low dose rate irradiation on CL187 colorectal cancer cells. Radiat Oncol 8 : 196, 2013.

10. Guo JH, Teng GJ, Zhu GY, He SC, Fang W, Deng G and Li GZ: Self-expandable esophageal stent loaded with $125 \mathrm{I}$ seeds: Initial experience in patients with advanced esophageal cancer Radiology 247: 574-581, 2008.

11. Zhu HD, Guo JH, Mao AW, Lv WF, Ji JS, Wang WH, Lv B, Yang RM, Wu W, Ni CF, et al: Conventional stents versus stents loaded with (125)iodine seeds for the treatment of unresectable oesophageal cancer: A multicentre, randomised phase 3 trial. Lancet Oncol 15: 612-619, 2014.

12. Chen HL, Shen WQ and Liu K: Radioactive self-expanding stents for palliative management of unresectable esophageal cancer: A systematic review and meta-analysis. Dis Esophagus 30: 1-16, 2017.

13. Qu A, Wang H, Li J, Wang J, Liu J, Hou Y, Huang L and Zhao Y: Biological effects of (125)i seeds radiation on A549 lung cancer cells: G2/M arrest and enhanced cell death. Cancer Invest 32 209-217, 2014

14. Wang ZM, Lu J, Zhang LY, Lin XZ, Chen KM, Chen ZJ, Liu FJ, Yan FH, Teng GJ and Mao AW: Biological effects of low-dose-rate irradiation of pancreatic carcinoma cells in vitro using 125I seeds. World J Gastroenterol 21: 2336-2342, 2015

15. Kim BM, Hong Y, Lee S, Liu P, Lim JH, Lee YH, Lee TH, Chang KT and Hong Y: Therapeutic implications for overcoming radiation resistance in cancer therapy. Int J Mol Sci 16 : 26880-26913, 2015.

16. Hu L, Wang $\mathrm{H}$, Zhao $\mathrm{Y}$ and Wang J: (125)I seeds radiation induces paraptosis-like cell death via PI3K/AKT signaling pathway in HCT116 cells. Biomed Res Int 2016: 8145495, 2016.

17. Chaurasia M, Bhatt AN, Das A, Dwarakanath BS and Sharma K Radiation-induced autophagy: Mechanisms and consequences. Free Radic Res 50: 273-290, 2016.

18. Leidal AM, Levine B and Debnath J: Autophagy and the cell biology of age-related disease. Nat Cell Biol 20: 1338-1348, 2018

19. Lu C and Xie C: Radiation-induced autophagy promotes esophageal squamous cell carcinoma cell survival via the LKB1 pathway. Oncol Rep 35: 3559-3565, 2016.

20. Tao H, Qian P, Lu J, Guo Y, Zhu H and Wang F: Autophagy inhibition enhances radiosensitivity of Eca109 cells via the mitochondrial apoptosis pathway. Int J Oncol 52: 1853-1862, 2018.
21. Lee D, Kim IY, Saha S and Choi KS: Paraptosis in the anti-cancer arsenal of natural products. Pharmacol Ther 162: 120-133, 2016.

22. Prokhorova EA, Egorshina AY, Zhivotovsky B and Kopeina GS: The DNA-damage response and nuclear events as regulators of nonapoptotic forms of cell death. Oncogene 39: 1-16, 2020.

23. Chen X, Chen X, Zhang X, Wang L, Cao P, Rajamanickam V, Wu C, Zhou H, Cai Y, Liang G and Wang Y: Curcuminoid B63 induces ROS-mediated paraptosis-like cell death by targeting TrxR1 in gastric cells. Redox Biol 21: 101061, 2019.

24. Fontana F, Moretti RM, Raimondi M, Marzagalli M, Beretta G, Procacci P, Sartori P, Montagnani Marelli M and Limonta P: delta-Tocotrienol induces apoptosis, involving endoplasmic reticulum stress and autophagy, and paraptosis in prostate cancer cells. Cell Prolif 52: e12576, 2019.

25. Seo MJ, Lee DM, Kim IY, Lee D, Choi MK, Lee JY, Park SS, Jeong SY, Choi EK and Choi KS: Gambogic acid triggers vacuolization-associated cell death in cancer cells via disruption of thiol proteostasis. Cell Death Dis 10: 187, 2019.

26. Zhao H, Xu X, Lei S, Shao D, Jiang C, Shi J, Zhang Y, Liu L, Lei S, Sun H and Huang Q: Iturin A-like lipopeptides from Bacillus subtilis trigger apoptosis, paraptosis, and autophagy in Caco-2 cells. J Cell Physiol 234: 6414-6427, 2019.

27. Kessel D: Apoptosis, paraptosis and autophagy: Death and survival pathways associated with photodynamic therapy. Photochem Photobiol 95: 119-125, 2019.

28. Weinberg F and Chandel NS: Reactive oxygen species-dependent signaling regulates cancer. Cell Mol Life Sci 66: 3663-3673, 2009.

29. Aird EG, Folkard M, Mayes CR, Bownes PJ, Lawson JM and Joiner MC: A purpose-built iodine-125 irradiation plaque for low dose rate low energy irradiation of cell lines in vitro. Br J Radiol 74: 56-61, 2001.

30. Gan Z, Jing J, Zhu G, Qin Y, Teng G and Guo J: Preventive effects of (1)(2)(5)I seeds on benign restenosis following esophageal stent implantation in a dog model. Mol Med Rep 11: 3382-3390, 2015.

31. Fernandez-Capetillo O, Chen HT, Celeste A, Ward I, Romanienko PJ, Morales JC, Naka K, Xia Z, Camerini-Otero RD, Motoyama N, et al: DNA damage-induced G2-M checkpoint activation by histone H2AX and 53BP1. Nat Cell Biol 4: 993-997, 2002.

32. Chen YS, Song HX, Lu Y, Li X, Chen T, Zhang Y, Xue JX, Liu H, Kan B, Yang $\mathrm{G}$ and $\mathrm{Fu} \mathrm{T}$ : Autophagy inhibition contributes to radiation sensitization of esophageal squamous carcinoma cells. Dis Esophagus 24: 437-443, 2011.

33. Shubin AV, Demidyuk IV, Komissarov AA, Rafieva LM and Kostrov SV: Cytoplasmic vacuolization in cell death and survival. Oncotarget 7: 55863-55889, 2016.

34. Zaorsky NG, Davis BJ, Nguyen PL, Showalter TN, Hoskin PJ, Yoshioka Y, Morton GC and Horwitz EM: The evolution of brachytherapy for prostate cancer. Nat Rev Urol 14: 415-439, 2017.

35. Wu C, Li B, Sun G, Peng C and Xiang D: Efficacy and safety of iodine-125 brachytherapy combined with chemotherapy in the treatment of advanced NSCLC in the elderly. Onco Targets Ther 11: 6617-6624, 2018.

36. Lehnert S, Reniers B and Verhaegen F: Relative biologic effectiveness in terms of tumor response of 125I implants compared with 60Co gamma rays. Int J Radiat Oncol Biol Phys 63: 224-229, 2005.

37. Liu C, Wang L, Qiu H, Dong Q, Feng Y, Li D, Li C and Fan C: Combined strategy of radioactive (125)I seeds and salinomycin for enhanced glioma chemo-radiotherapy: Evidences for ROS-mediated apoptosis and signaling crosstalk. Neurochem Res 43: 1317-1327, 2018.

38. Zhang WF, Jin WD, Li B, Wang MC, Li XG, Mao WY and Luo KY: Effect of brachytherapy on NF-kB and VEGF in gastric carcinoma xenografts. Oncol Rep 32: 635-640, 2014.

39. Lee DM, Kim IY, Seo MJ, Kwon MR and Choi KS: Nutlin-3 enhances the bortezomib sensitivity of p53-defective cancer cells by inducing paraptosis. Exp Mol Med 49: e365, 2017.

40. Zhou Y, Huang F, Yang Y, Wang P, Zhang Z, Tang Y, Shen Y and Wang K: Paraptosis-inducing nanomedicine overcomes cancer drug resistance for a potent cancer therapy. Small 14: 2018

41. Kim JY, Lee DM, Woo HG, Kim KD, Lee HJ, Kwon YJ and Choi KS: RNAi screening-based identification of USP10 as a novel regulator of paraptosis. Sci Rep 9: 4909, 2019.

42. Sperandio S, de Belle I and Bredesen DE: An alternative, nonapoptotic form of programmed cell death. Proc Natl Acad Sci USA 97: 14376-14381, 2000.

43. Wang G, Liu L, Sharma S, Liu H, Yang W, Sun X and Dong Q: Bmi-1 confers adaptive radioresistance to KYSE-150R esophageal carcinoma cells. Biochem Biophys Res Commun 425: 309-314, 2012. 
44. Zhang $\mathrm{H}$, Luo H, Jiang Z, Yue J, Hou Q, Xie R and Wu S: Fractionated irradiation-induced EMT-like phenotype conferred radioresistance in esophageal squamous cell carcinoma. J Radiat Res 57: 370-380, 2016.

45. Mirzayans R, Andrais B, Scott A, Wang YW, Kumar P and Murray D: Multinucleated giant cancer cells produced in response to ionizing radiation retain viability and replicate their genome. Int J Mol Sci 18: E360, 2017.

46. Denisenko TV, Sorokina IV, Gogvadze V and Zhivotovsky B: Mitotic catastrophe and cancer drug resistance: A link that must to be broken. Drug Resist Updat 24: 1-12, 2016.

47. Weihua Z, Lin Q, Ramoth AJ, Fan D and Fidler IJ: Formation of solid tumors by a single multinucleated cancer cell. Cancer 117 4092-4099, 2011.

48. Srinivas US, Tan BWQ, Vellayappan BA and Jeyasekharan AD: ROS and the DNA damage response in cancer. Redox Biol 25 101084, 2019.
49. Zou Z, Chang H, Li H and Wang S: Induction of reactive oxygen species: An emerging approach for cancer therapy. Apoptosis 22 : 1321-1335, 2017

50. Tang JY, Ou-Yang F, Hou MF, Huang HW, Wang HR, Li KT, Fayyaz S, Shu CW and Chang HW: Oxidative stress-modulating drugs have preferential anticancer effects-involving the regulation of apoptosis, DNA damage, endoplasmic reticulum stress, autophagy, metabolism, and migration. Semin Cancer Biol 58: 109-117, 2019.

(i) () $($ This work is licensed under a Creative Commons EY No Attribution-NonCommercial-NoDerivatives 4.0 International (CC BY-NC-ND 4.0) License. 